\section{A. ARS BILDUMa \\ ISSN 1989-9262 \\ UPV/EHU Press}

ARSBILDUMA (CC BY-NC-ND 4.0)

https://doi.org/10.1387/ars-bilduma.22127

BIBLID [(2021), 11; 107-125]

Recibido: 06/07/2020 Aceptado: 06/10/2020

\section{JAVIER GÓMEZ DARRIBA}

Universidade de Santiago de Compostela

Praza da Universidade, 1

15782 Santiago de Compostela (A Coruña)

javier.gomez.darriba@usc.es

https://orcid.org/0000-0001-6712-2983

Este trabajo se enmarca dentro del Proyecto I+D+i (PGC Tipo B) Memoria del patrimonio arquitectónico desaparecido en Galicia. El siglo XX, PID2019105009GB-I00, concedido por el Ministerio de Ciencia e Innovación para el periodo 2020-2022, y que cuenta con Alfredo Vigo Trasancos y Jesús Ángel Sánchez García como investigadores principales.

\title{
LOS ARTIAGA: LA ACTIVIDAD ARTÍSTICA DE UNOS MAES- TROS CANTEROS VIZCAÍNOS EN GALICIA (1560-1600)
}

THE ARTIAgAS: THE ARTISTIC ACTIVITY OF SOME BISCAYAN MASTER STONEMASONS IN GALICIA (1560-1600)

\author{
OS ARTIAGA: A ACTIVIDADE ARTÍSTICA DUNS MESTRES CANTEIROS \\ BISCAÍÑOS EN GALICIA (1560-1600)
}

RESUMEN

Los vizcaínos Pedro y Francisco de Artiaga desempeñaron su actividad como maestros de obras en la Galicia de la segunda mitad del siglo XVI. En concreto en dos capitales provinciales y episcopales como Lugo y Mondoñedo, donde trabajaron para ambas catedrales, diseñaron y construyeron sendas casas consistoriales, y realizaron multitud de obras públicas. Puesto que apenas resultan conocidos por la historiografía, en el presente artículo abordaremos su biografía carrera profesional y personalidad artística.

PALABRAS CLAVE

Pedro de Artiaga; Francisco de Artiaga, arquitectura; urbanismo; Galicia; siglo XVI.

\section{ABSTRACT}

The Biscayans Pedro and Francisco de Artiaga carried out their activity as master builders in Galicia in the second half of the 16th century. In particular in two provincial and episcopal capitals such as Lugo and Mondoñedo, where they worked for both cathedrals, designed and built two town halls and carried out many public works. Since they are a little known in historiography, in this paper we will analyze their biography, professional career, and artistic personality.

KEYWORDS

Pedro de Artiaga; Francisco de Artiaga; architecture; urbanism; Galicia; 16th century.
RESUMO

Os biscaíños Pedro e Francisco de Artiaga desempeñaron a súa actividade como mestres de obras na Galicia da segunda metade do século XVI. En concreto en dúas capitais provinciais e episcopais como Lugo e Mondoñedo, onde traballaron para ambas catedrais, diseñaron e construíron sendas casas consistoriais, e realizaron multitude de obras públicas. Posto que apenas resultan coñecidos pola historiografía, no presente artigo abordaremos a súa biografía, carreira profesional e personalidade artística.

\section{PALABRAS CLAVE}

Pedro de Artiaga; Francisco de Artiaga; arquitectura; urbanismo; Galicia; século XVI. 


\section{INTRODUCCIÓN}

En la segunda mitad del siglo XVI el Reino de Galicia constituía una provincia de la Corona de Castilla. Este territorio se subdividía a su vez en siete provincias con sus respectivas capitales. Cuatro de ellas eran también sedes episcopales, caso de Lugo y Mondoñedo, dos pequeños núcleos urbanos situados al noreste de la región que rondaban el millar de habitantes ${ }^{1}$. Durante este tiempo sus instituciones rectoras, esto es, la Iglesia local como responsable del poder espiritual y el Ayuntamiento como representante del poder civil, requirieron de arquitectos que delineasen distintos espacios litúrgicos y obras de carácter público, tales como puentes, fuentes, calzadas, puertas en las murallas, etc. Muy frecuentemente reclamaron artistas procedentes de la cornisa cantábrica, especialmente trasmeranos ${ }^{2}$. Pero también existió una minoritaria presencia de maestros vizcaínos, caso de Pedro y de Francisco de Artiaga ${ }^{3}$. Todo parece indicar que eran padre e hijo, pero no hemos hallado documento alguno que certifique dicho parentesco. Tampoco se conocen sus fechas de nacimiento y muerte. No obstante, dado el conjunto de datos que siguen a estas líneas, cabe suponer que Pedro vivió aproximadamente entre 1530-1590, y que Francisco lo hizo hacia 1560-1620. El primero llegó a Mondoñedo en 1560 y constató que resultaba una localidad carente de arquitectos. La falta de competencia en el ejercicio de su profesión hubo de ser la principal causa para que decidiese establecerse allí hasta 1587. En este tiempo recibió todo tipo de encargos de la Iglesia local y del Consistorio, lo cual no impidió que puntualmente acudiese a Lugo a diseñar edificios o a intentar adjudicars

SAAVEDRA FERNÁNDEZ, P.: Economía, Política y Sociedad en Galicia: la provincia de Mondoñedo. Madrid, Xunta de Galicia, 1985, pp. 50-52; PEIRO GRANER, M.N.: "A poboación da cidade de Lugo n século XVI Catro inventarios (1542, 1543, 1544 e 1587)" Lucensia n o 4, 1992, pp. 69-82. SOBRADO Cl Antiguo Régimen. Siglos XVI-XIX. Lugo, Diputación de Lugo, 2001, pp. 15-16, 27-32

2 GOY DIZ, A. "Ios trasmeranos en Galicia: la familia de los Arce", en ARAMBURU-ZABALA HIGUERA, M.A. (Dir.): Juan de Herrera y su influencia. Actas del Simposio. Camargo, $14-17$ julio 1992 Santander, Fundación Obra Pía Juan de Herrera, Universidad de Cantabria, 1993, pp. 147-163; DÚo RÁMILA, D.: "Maestros canteros de Trasmiera en Galicia (siglo XVI)", Espacio, Tiempo y Forma. Serie VII, Historia del Arte, n. ${ }^{\circ} 24,2011$, pp. 81-100; GÓMEZ DARRIBA, J.: La ciudad de Mondoñedo en los siglos XVII y XVIII. Construcción y nueva imagen de un centro de poder episcopal. Santiago de Compostela. Universidade de Santiago de Compostela (Tesis Doctoral), 2020

3 Recientemente a Pedro se le ha considerado trasmerano sin mayor justificación, GOY DIZ, A.: "Proyecto para las Casas Consistoriales de Lugo (1570)", en IBÁÑEZ FERNÁNDEZ, J. (coord.): Trazas, mues tras y modelos de tradición gótica en la Península Ibérica entre los siglos XIII y XVI. Madrid, Instituto Juan de Herrera, 2019, p. 524 construcciones de diversa índole. Desde 1584 Francisco continuó en Mondoñedo la labor iniciada por su pariente, manteniendo el mismo perfil de maestro de obras hasta 1595. A partir de entonces nada más se vuelve a saber de él, salvo que a inicios del siglo XVII ejercía como maestro cantero en Noja (Cantabria) ${ }^{4}$. La presencia de ambos en el Reino de Galicia desde finales del tercio central del siglo XVI coincide con el apogeo que experimentaron entonces los profesionales de la arquitectura y la cantería vasca, cuya buena fama les llevó a expandirse por decenas a lo largo y ancho de la península ibérica, atendiendo a la llamada de diversas instituciones clericales y civiles que los requerían para que levantasen nuevas fábricas edilicias. Este fenómeno originó talleres itinerantes que, en ocasiones, terminaron por asentarse en un determinado sitio durante décadas, perviviendo a veces de forma endogámica, algo que se ejemplariza en el caso de los Artiaga ${ }^{5}$.

Algunos de los manuscritos que citan a ambos maestros, o que incluso aparecen firmados por ellos, indican que eran "vizcaynos", pero no concretan su lugar de origen, ni tampoco la procedencia desde otros centros artísticos (figs. 1 y 2). La más completa referencia a profesionales de la construcción de oriundez vasca apellidados Artiaga o Arteaga se halla en un extenso artículo de Barrio Loza y Moya Valgañón. Allí se cita al Pedro de Artiaga aqui objeto de estudio y también a un homónimo que en 1558 trabajaba en Lanjarón (Granada). Asimismo, se reseña un Pedro Arteaga que trabajó para la iglesia de Pampliega (Burgos) entre 1549-1550; y a otro personaje de igual nombre que en 1561 examinó las obras de la iglesia de Añúa (Elburgo, Álava). No se alude sin embargo a Francisco de Artiaga ni existe ningún otro dato que aclare la relación entre los maestros ahora analizados con otros de idéntico apellido ${ }^{6}$. Tampoco hay ninguna certeza que vincule a Francisco con un ensamblador llamado Francisco de Arteaga, que en la década de 1560 colaboró con el escultor Adrián de Bedoya en la realización del retablo mayor de la iglesia parroquial de

4 CAGIGAS ABERASTURI, A I. Los maestros canteros de Trasmiera. Santander. Universidad de Cantabria, 2015, p. 593. https://repositorio.unican.es/xmlui/handle/10902/8345 (Consultado el 01/06/2018) Acerca del referido éxito de los arquitectos y canteros de origen vasco en el siglo XVI, véase la bibliografía citada entre las notas 6 y 11 .

6 BARRIO LOZA, J.A., MOYA VALGAÑÓN, J.G.: "Los Canteros Vizcaínos (1500-1800): Diccionario Biográfico", Kobie, n.o 11, 1981, pp. 193-194. Véase también MOYA VALGANON, J.G.: Arquitectura religiosa del siglo XVI en la Rioja Alta. Logroño, Instituto de Estudios Riojanos, 1980, p. 93; URRESTI SANZ V: Arquitectura religiosa del Renacimiento en Álora (1530-1611). Vitoria-Gasteiž Oniversided Rs://addi.ehu.es/handle/10810/1: También se desconoce la relación entre los maestros objeto de estudio con Juan y Martín de Artiaga quienes trabajaron para el Ayuntamiento de Sevilla entre 1528 y 1541, MORALES, A.J.: "El Ayuntamiento de Sevilla: maestros canteros, entalladores e imagineros", Laboratorio de Arte, n. ${ }^{\circ} 4,1991$, pp. 66-67. 
Nuestra Señora de la Asunción de Baró (Camaleño, Cantabria) 7 . Publicaciones posteriores a las de Barrio Loza y Moya Valgañón acrecentaron el conocimiento sobre canteros con dichos nombres, caso de Pedro Ortiz de Artiaga, a quien se le supone trabajando en 1529 en la iglesia de Santa María de la Redonda (Logroño) ${ }^{8}$; o de Pedro de Arteaga -natura de Amasa-Villabona (Guipúzcoa) para unos y de Tolosa (Guipúzcoa) para otros-, que trabajó en las décadas de 1560-1570 en distintos edificios de la Ribera Navarra, destacando entre todos ellos el claustro del monasterio de Santa María de Fitero9. Existió otro Pedro de Arteaga cantero y vecino de Munain (San Millán, Álava), donde compartió oficio con su hermano Asensio y tuvo tres hijos llamados Juan, María y Benito. Desde luego no se trata del que aquí es objeto de estudio porque falleció en $1617^{10}$. Lo cierto es que ni el Pedro ni el Francisco de Artiaga que centran nuestra atención aparecen citados en otras investigaciones dedicadas a la arquitectura de las antiguas diócesis de Calahorra, Pamplona y Tudela durante el siglo XVI y primer cuarto del XVII ${ }^{11}$, lo cual es indicativo de que la mayor parte de su actividad artística la debieron desarrollar lejos de su lugar de origen, y muy especialmente en Galicia.

POLO SÁNCHEZ, J.J.: "Aportaciones a la escultura renacentista en Cantabria: Simón de Bueras y Adrián de Bedoya", Boletín del Seminario de Estudios de Arte y Arqueología, n. ${ }^{\circ}$ 52, 1986, pp. 317-318.

8 ÁLVAREZ CLAVIJO, M.T.: Logroño en el siglo XVI: arquitectura y urbanismo. Logroño, Gobierno de La Rioja, Ayuntamiento de Logroño, Instituto de Estudios Riojanos, 2003, vol. 2, p. 282

9 ECHEVERRÍA GOÑI, P.L., FERNÁNDEZ GRACIA, R.: "Arquitectura", en FERNÁNDEZ GRACIA, R. (coord.): El arte del Renacimiento en Navarra. Pamplona, Gobierno de Navarra, 2005, pp. 146-147 TARIFA CASTILLA, M.J.: La arquitectura religiosa del siglo XVI en la Merindad de Tudela. Pamplona, Gobierno de Navarra, 2005, pp. 107-108, 428-437.

10 BALLESTEROS IZQUIERDO, T.: Actividad artística en Vitoria durante el primer tercio del siglo XVII: Arquitectura. Vitoria-Gasteiz, Diputación Foral de Álava, 1990, p. 176.

11 De entre todas ellas merecen señalarse las siguientes por no haber sido citadas hasta el momento: SES-

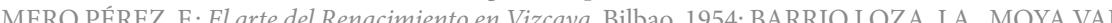
GAÑÓN J. "El modo dasco de prodcción ar 1980, pp. 283-369; BCHEVERR Á GOÑ Vitoria 283-369, ECHEVERRIA GONA, P.L., GONZALEZ DE ZARATE, J.M.: Vitoria renacentista.

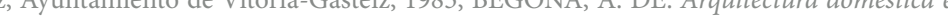
la Llanada de Álava. Siglos XVI, XVII y XVIII. Vitoria-Gasteiz, Diputación Foral de Álava, 1986; CALATAYUD FERNÁNDEZ, E.: Arquitectura religiosa en la Rioja Baja: Calahorra y su entorno (1500-1650). Madrid, Universidad Complutense de Madrid, 1987, 7 vols.; ARRAZOLA ECHEVERRÍA, M.A.: Re nacimiento en Guipúzcoa. Arquitectura. San Sebastián, Diputación Foral de Guipúzcoa, 1988; BARRIO LOZA, J.A. (Dir): Bizkaia. Arqueología, urbanismo y arquitectura histórica. Bilbao, Universidad de

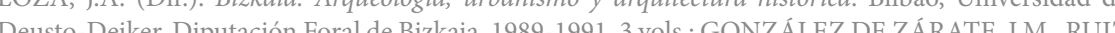
DE AEL Ma Hursmo y arte en la Universidad de Oñte. VitoriaMARTÍNEZ DE SALINAS OCIO, F:: Arquitectura y urbanismo de Laguardia (Álava). (De la Edad Me dia al primer tercio del siglo XIX). Vitoria-Gasteiz, Diputación Foral de Álava, 1991; VILA JATO, M.D.

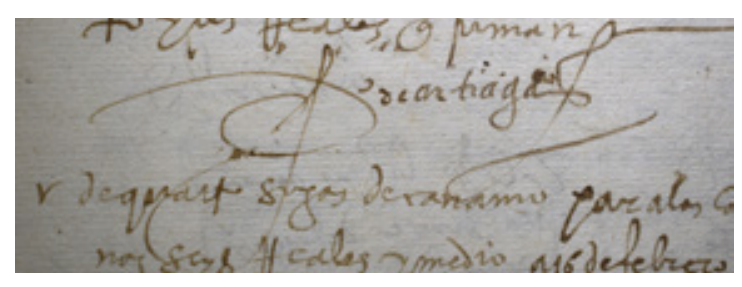

Fig. 1: Firma de Pedro de Artiaga. 1573. ACL, Estante 16, Libro de Fábrica (1567-1609), f. 66r

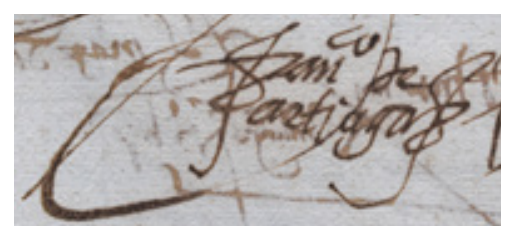

Fig. 2: Firma de Francisco de Artiaga. 1587. AMM, Carp. 922, Libro de Actas (1586-1595), f. $41 \mathrm{v}$ 


\section{LA FIGURA DE PEDRO DE ARTIAGA}

Pedro de Artiaga llegó a Mondoñedo no más tarde del 17 de septiembre de 1560 junto con su compañero Francisco Blanco para pujar por las obras de distintos caminos calzadas, comprometiéndose a extraer y labrar la piedra a razón de 4,5 reales la braza ${ }^{12}$. $\mathrm{Al}$ año siguiente se adjudicaron el empedrado de todas las calles de la ciudad, labor que mantuvo ocupado a Artiaga hasta $1567^{13}$. Es muy probable que en todo este tiempo acometiese en la urbe otro tipo de obras que le otorgasen cierto prestigio como aparejador, pero documentalmente no se le acredita ninguna hasta 1568. Entonces el obispo Gonzalo de Solórzano y el fabriquero y maestrescuela Lope Martínez de Praveo le encargaron que hiciese en la catedral "los quartos del cavildo y los mas de la claustra", o lo que es lo mismo, una nueva sala capitular ${ }^{14}$. El edificio se levantaría sobre el solar que ocupaba desde el siglo XIV la capilla de San Andrés, advocación que mantuvo el nuevo capítulo, que también conservó el sobrenombre medieval de Paaço dos Cabaleiros por las muchas laudas de caballeros que enlosaban su suelo ${ }^{15}$. El recinto sufrió reformas a partir de 1745

"Canteros cántabros y vizcaínos en el primer Renacimiento gallego", en Homenaje al Profesor Martín González. Valladolid, Universidad de Valladolid, 1995, pp. 275-277; FORNELLS ANGELATS, M. La Universidad de Oñati el Renacimiento. Donostia-San Sebastín, Diputación Foral de Guipuzcoa 1995 , MARTIN MII tamiento de Vitoria-Gasteiz, 1998; CENDOYA ECHANIZ, J.: Arquitectura conventual en Guipúzcoa (S. XVI-XVIII). Las franciscanas. San Sebastián, Editorial Franciscana Aránzazu, 1999; CASTRO SANTAMARÍA, A.: Juan de Álava. Arquitecto del Renacimiento. Salamanca, Caja Duero, 2002; ARAMBURU EXPÓSITO, M.J.: Arte y piedad. El arte religioso en Bergara en la Edad Moderna. Bergara, Ayuntamiento de Bergara, 2008, 2 t.; AYERZA ELIZARAIN, R.: Iglesias de madera en Gipuzkoa. Bilbao, Universidad del País Vasco, 2019.

12 Arquivo Municipal de Mondoñedo [AMM], Carp. 919, Libro de Actas (1560-1565), 1560, s.f.; GOY DIZ, A.: "La difícil empresa de llevar el agua a la ciudad de Lugo: traídas, caños y fuentes", en GOY DIZ, A., PATIÑO EIRÍN, C. (eds.): El tapiz humanista II. Actas del XI Curso de Primavera IV Centenario de la Segunda Parte del Quijote. Lugo 21-23 de abril de 2015. Santiago de Compostela, Universidade de Santiago de Compostela, 2017, pp. 129-132

13 AMM, Carp. 919, Libro de Actas (1560-1565), 1561, 1562, 1563, 1564, 1565, s.f.; Carp. 920, Libro de Actas (1566-1573), f. 23r.

14 La escritura pasó ante el notario Álvaro Rodríguez de Pedrosa. Artiaga cobraría por su trabajo 344 ducados y la Iglesia pondría a su disposición 100 carros de cantería proveniente de los cercanos montes de O Valiño y Os Picos, Archivo de la Catedral de Mondoñedo [ACM] arm 7 est 2 leg 8 , o 10 . s.

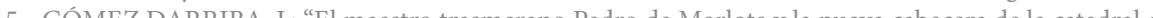
Mondoñedo", Quintana, n. $.^{\circ} 17,2018$, p. 240. Existen decenas de referencias de la década de 1570 y de lo primeros años de la consecutiva que aluden a dicho recinto como "cuarto nuevo del claustro", "cuarto nuevos de la Capilla de S. Andrés" u otras menciones semejantes, CAL PARDO, E.: Mondoñedo -Cate- por iniciativa del obispo fray Antonio Alejandro Sarmiento, quien gozó de la potestad del Cabildo para convertirlo en una capilla dedicada a san Ignacio ${ }^{16}$. En la actualidad alberga una sala del Museo Catedralicio y Diocesano. De la sala capitular levantada por Artiaga apenas se conserva el escudo del obispo promotor sobre la portada que la comunicaba con el claustro ${ }^{17}$, así como un par de basas poligonales en las que se entremezclan boceles y escocias labradas con rombos. Este arco lo reformó el arquitecto trasmerano Diego Ibáñez Pacheco entre 1637-1639, quien lo dotó de mayor tamaño ${ }^{18}$

Desde la obra de la sala capitular en 1568 no hay constancia de que Pedro de Artiaga volviese a trabajar para la catedral mindoniense hasta 1584. Entonces el obispo Isidro Caja de la Jara ordenó extraer el reloj que se disponía sobre la portada de la fachada y llevarlo a una de las torres "por el peligro e indeçençia de las pesas q caen delante de la puerta prinçipal de la iglesia, y se saque una mano o indice a la Plaça" ${ }^{\prime \prime}$. El Cabildo contrató el traslado del mismo y el de su campana a Artiaga, quien a su vez contactó al año siguiente con el cerrajero mindoniense Francisco Perrote y con su colega Manualín Francés, vecino de Ribadeo (Lugo), para que efectuasen la mudanza hasta la torre meridional aneja al Palacio Episcopal, rebautizada como Torre del Reloj ${ }^{20}$

En el primer lustro de la década de 1570 Artiaga también trabajó para el Cabildo de la catedral de Lugo. En 1572 fue contratado para realizar "los presdestrales del arco para la rexa [...] de la capilla mayor", obra que lo mantuvo ocupado hasta el año siguiente. Cobró

dral, Ciudad, Obispado- en el siglo XVI. Catálogo de la documentación del Archivo Catedralicio. Santiago de Compostela, Xunta de Galicia, 1992, pp. 334, 336, 340, 407, 414, 419, 438, 441, 501, 503, 524.

16 ACM, Actas Capitulares, vol. 19, ff. 26v, 30r; Cuentas de la Fábrica, vol. 28-2, ff. 14r-15r; CAL PARDO, E. "Sacristía y Custodia de la Catedral Basílica de Mondoñedo" Estudios Mindonienses, no 3, 1987, p. 552. Para entonces este espacio ya no era sala capitular Entre 1734-1735 se habí decidido realizar nueva en las estancias que antaño habian seevido de archivo. Esta idea ya había sido aprobada en 172 pero no se materializó hasta mediada la década siguiente, ACM, Actas Capitulares, vol. 17, f. 99r y vol. 18, ff. 1v, 2v, 46v, 48r, 50v, 59v, 93r; arm. 7, est. 3, leg. 6, s.n. ${ }^{\circ}$, s.f. y n. ${ }^{\circ}$ 39, s.f.; CAL PARDO, E.: Episcopologio Mindoniense. Santiago de Compostela, CSIC-Xunta de Galicia, Instituto de Estudios Gallegos "Padre Sarmiento"; Mondoñedo-Ferrol, Estudios Mindonienses, 2003, p. 720.

17 RÚA VELOSO, O.: Heráldica del Municipio de Mondoñedo. Lugo, Diputación Provincial de Lugo, 2005, p. 27.

18 ACM, Actas Capitulares, vol. 11, ff. 323v-324r, 332v, 426v-427r; CAL PARDO, E.: Episcopologio..., op cit., p. 508 .

19 ACM, Miscelánea, arm. 4, est. 1, leg. 2, n.o 6, s.f.; CAL PARDO, E.: Mondoñedo-Catedral, Ciudad . op. cit., p. 873. 
por ella 24 ducados. Las cuentas de la fábrica registran varios pagos al vizcaíno y asimismo al entallador que hizo la escultura mariana que coronó la reja, como también al pintor vallisoletano Marcos de Torres por dorar "los tondos de las medallas de la reja"21. De la ejecución del hierro para la misma se habían encargado los cerrajeros Pedro de Sobrado y Baltasar Rous ${ }^{22}$. La citada contabilidad también indica que Artiaga recibió otros 2 ducados con 4 reales por hacer "los pasos del coro y de los pulpitos y de la entrada de la yglesia"23. Escasos años después, entre junio y julio de 1575, pugnó junto con Gregorio do Barrio por la adjudicación de la obra de la Torre de las Campanas, que finalmente tomó el arquitecto trasmerano Gaspar de $\mathrm{Arce}^{24}$.

Aparte de las calzadas citadas y de las casas consistoriales que pronto analizaremos, Pedro de Artiaga realizó una serie de obras públicas para los Ayuntamientos de Lugo y Mondoñedo. En 1570 el Concejo lucense reconoció la urgencia por arreglar varios puentes, calzadas, la fuente del Castiñeiro y por supuesto levantar una Casa de Consistorio. A finales de año, Artiaga compareció en la ciudad con la intención de adjudicarse todas estas obras, declarando ser un maestro cantero facultado para ello. También reconoció su oriundez vizcaína y su vecindad mindoniense. A juicio de Goy Diz puede que desde inicios de 157 emprendiera el arreglo del conducto del manantial del Castiñeiro, aunque la autora vincula el diseño del mismo al trasmerano Gonzalo de la Bárcena, el más prestigioso maestro fontanero de la Corona de Castilla por aquel entonces ${ }^{25}$.

21 Archivo de la Catedral de Lugo [ACL], Estante 16, Libro de Fábrica (1567-1609), ff. 58v, 59v-60r, 63v, 65r, 66r, 72r. Las cuentas aluden al citado pintor por su apellido, pero sin duda alguna se trata de Marcos de Torres, quien trabajó para la catedral lucense con prolijidad en la década de 1570, siendo el autor de la policromía y dorado del retablo mayor, PÉREZ COSTANTI, P.: Diccionario de artistas que florecieron en Galicia durante los siglos XVI y XVII. Santiago, Seminario C. Central, 1930, pp. 307, 531-532.

$22 \mathrm{Ibid.}, \mathrm{p} .518$. Acerca de estos profesionales y de su trabajo en la reja existen centenares de menciones en el ACL, Estante 16, Libro de Fábrica (1567-1609).

23 Ibid., f. 66r.

24 CALleS LOMBAO, M.G.: "La Torre de los Signos de la Santa Iglesia Catedral Basílica de Lugo (1575 1583), nuevos documentos localizados en los archivos lucenses", Abrente, n. ${ }^{\circ} 49-50,2017-2018$, pp. 3 y ss.

25 LÓPEZ ACUÑA, A.: "Las Casas Consistoriales lucenses", Boletín de la Comisión provincial de Monumentos Históricos y Artísticos de Lugo, t. 4, n. ${ }^{\circ} 33,1950$, pp. 56-57; GOY DIZ, A.: "La difícil empresa..."

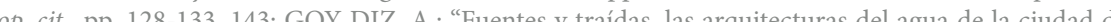

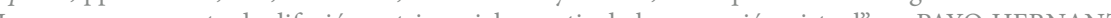
Lugo. tha propuesta de difusion patrie "Fu a patir de h R.J. et al. (eds.): Vestir la arquitectura. XXII Congreso Nacional de Historia del Arte. Burgos, Universidad de Burgos, 2019, vol. 2, p. 1610
En el verano de 1579 el Ayuntamiento de Mondoñedo lo requirió para que acometiese una reforma en la puerta de la muralla más importante de la ciudad, la Porta da Fonte, y asimismo en el puentecillo que la unía con la plazuela inmediata conocida como de la Fuente Vieja. Dicha infraestructura servía para salvar el cauce del río de Sixto, que no era más que un arroyo utilizado en el Medievo como foso de la cerca. El arreglo de dicha portada se financió con dinero de las arcas municipales y también con alguna aportación del obispo Juan de Liermo. El gesto del prelado motivó que el Concejo lo gratificase disponiendo su escudo de armas en la fachada de la Casa Consistorial ${ }^{26}$. Desgraciadamente, de todo lo dicho solo se conserva el blasón del obispo, como luego veremos, pues la puerta y el lienzo de la muralla sufrieron graves desperfectos y reformas desde finales del siglo XVI en adelante, terminando por desaparecer en $1834^{27}$.

\subsection{Las Casas Consistoriales de Mondoñedo y Lugo}

En 1480 los Reyes Católicos emitieron el ordenamiento 106 de las Cortes de Toledo por el cual se instaba a las principales villas y ciudades del reino a levantar edificios de digna arquitectura que sirviesen de ayuntamientos y que se hallasen emplazados en sitios preeminentes. No todas pudieron asumir de inmediato el costo de semejantes obras, pero la mayoría cumplieron con dicho dictamen a lo largo del siglo XVI, sirviéndose para ello de privilegios como la aprobación de sisas y repartimientos que contribuyesen a financiar los nuevos edificios públicos ${ }^{28}$. La corporación municipal de Mondoñedo aprobó construir la Casa de Concejo en 1569. La de Lugo hizo lo propio al año siguiente. Ambos consistorios se ubicaron en un lugar preferente dentro de la plaza principal de la urbe. En dichos foros se celebraban mercados, paradas militares, corridas de toros, procesiones, proclamaciones reales, etc. Resultaban en definitiva el lugar más bullicioso y ceremonial de la ciudad ${ }^{29}$. El

26 En diciembre de 1579 el Ayuntamiento le acabó de pagar a Artiaga los 48 ducados que le debía po estos trabajos, AMM, Carp. 921, Libro de Actas (1574-1586), ff. 222r-222v, 224v, 227r; Carp. 978, f. 55v PÉREZ COSTANTI, P.: Diccionario de artistas..., op. cit., pp. 48-49; LENCE-SANTAR Y GUITIÁN, E. "La muralla de Mondoñedo", Boletín de la Comisión provincial de Monumentos Históricos y Artísticos de Lugo, t. 4, n. ${ }^{\circ} 33,1950$, pp. $25-26$.

27 GÓMEZ DARRIBA, J.: La ciudad de Mondoñedo..., op. cit., pp. 79-81, 107-108.

28 GORDO PELÁEZ, LJ.: Equipamientos y edificios municipales en la Corona de Castilla en el siglo XVI. Madrid, Universidad Complutense de Madrid, 2010, pp. 164-171. http://eprints.ucm.es/10840/ (Consultado el 10/08/2020)

29 Sobre las plazas de ambas ciudades véase ABEL VILELA, A. DE: Urbanismo y arquitectura en Lugo. La Plaza Mayor. Sada, Ediciós do Castro, 1999; GÓMEZ DARRIBA, J.: La ciudad de Mondoñedo..., op. 
encargado de diseñar y dirigir estas obras fue Pedro de Artiaga. En los próximos párrafos analizaremos pormenorizadamente la gestación de cada una, el periodo de construcción, así como la tipología, morfología y particularidades varias.

En el caso de Mondoñedo cabe destacar que el obispo ostentaba el señorío de la ciudad desde el siglo XII. Allí regentaba el poder espiritual y en los siglos que siguieron a la fundación regia de 1156 poseyó también el temporal sin apenas oposición. Conforme fue avanzando la Baja Edad Media creció la representación civil y laica de los mindonienses. Ya en el siglo XVI, con la consolidación del estado moderno, la autonomía del poder civil respecto a la autoridad pontificia resultó mucho más notable. Sin embargo, durante todo el Antiguo Régimen, el poder temporal continuó supeditado al prelado, quien en última instancia ratificaba a los integrantes de la corporación municipa ${ }^{30}$. La soberanía lograda por el poder civil trajo consigo la independencia de sus ámbitos representativos. Tengamos en cuenta que desde aproximadamente el siglo XIII hasta principios del XV, los plenos municipales se celebraron en ciertos espacios del claustro de la catedral, llegando incluso a efectuarse en la vieja sala capitular ${ }^{31}$. En 1429 el Ayuntamiento tomó en foro las estancias de un inmueble abierto a la Plaza Pública y en él estableció la alhóndiga ${ }^{32}$. Al menos durante buena parte del siglo XVI este antiguo edificio de viviendas se convirtió en consistorio, pues las sesiones municipales tuvieron lugar alli ${ }^{33}$.

Hubo que esperar a octubre de 1569 para que el Concejo lograse iniciar el camino que conduciría a la materialización de una casa consistorial ad hoc. En aquel tiempo adquirió unas parcelas en el flanco noroccidental de la Plaza, esto es, en la zona más alta de la misma, ocupadas por unas viviendas arruinadas. Dicho emplazamiento implicaba erigir un edificio con dos fachadas. Una que mirase a la propia Plaza, y otra al espacio urbano conocido popularmente como Cantón Pequeño (figs. 3 y 4). Las obras se remataron en noviembre, tan

cit., pp. 112-12

30 LÓPEZ DÍAZ, M.: "Poder e instituciones municipales: el concejo mindoniense en los siglos XVI XVII", Sémata, n. ${ }^{\circ} 15,2003$, pp. 415-444

31 CARRERO SANTAMARÍA, E.: Las catedrales de Galicia durante la Edad Media. Claustros y entorno urbano. A Coruña, Fundación Pedro Barrié de la Maza, 2005, p. 155. Estancia que, como sabemos, reformaría el propio Artiaga en 1568.

32 CAL PARDO, E.: Catálogo de los documentos medievales, escritos en pergamino, del Archivo de la Catedral de Mondoñedo (871-1492). Lugo, Diputación Provincial de Lugo, 1990, p. 551; CAL PARDO, E. Tumbos de la Catedral de Mondoñedo. Tumbo Pechado. Transcripción integra de sus documentos. Tomos I $y$ II. Lugo, Diputación Provincial de Lugo, 2006, pp. 321-322 solo 56 días después de que el Ayuntamiento hubiese comprado los terrenos. Únicamente pujó por ellas Pedro de Artiaga, a quien le fueron adjudicadas en 200 ducados. De esta forma se convirtió en aparejador de las mismas, aunque con toda seguridad hubo de ser también el tracista. El escaso margen temporal que media entre la adquisición de los solares y la subasta de las obras induce a pensar que el Concejo no se preocupó de anunciar el proyecto por las distintas localidades del Reino de Galicia, sino que lo confió directamente Artiaga, quien llevaba ejerciendo su oficio en la ciudad desde 1560. Otro argumento para creer que fue él quien delineó el edificio lo supone el hecho de que entre 1570-1571 proyectase el homólogo lucense, el cual, como tendremos oportunidad de comprobar, guardaba evidentes similitudes con el mindoniense. Sea como fuere, en noviembre de 1569 el Ayuntamiento de Mondoñedo ordenó a Artiaga levantar el edificio de la siguiente manera: la fachada meridional tendría en su planta baja un soportal formado por tres arcos, columnas y un machón angular. Sobre la arcada montaría una pared perforada por cuatro ventanas "como las de las casas de luis de luazes de abadin", esto es, como las de la fachada de la Casa de Luaces, una vivienda palaciega construida en 1554 a escasos $70 \mathrm{~m}$ del Consistorio. Aparte de estos vanos, en el frontis de la Casa de Concejo también se abriría una puerta ventana "con su moldura rromana". Se supone que este último vano se hallaría en medio de los otros cuatro. Con toda seguridad en la parte central del frontispicio se encastrarían las armas imperiales, mientras que en los laterales se duplicaría el escudo del Reino de Galicia "con un guardapolbo". Culminaría la fachada "un antepecho de canteria con altura de tres palmos y encima la almena o rromano". El frente oriental se compondría de tres columnas "redondas de canteria con sus vasas", pero la documentación no concreta qué orden tendrían. La portada de acceso al edificio reiteraría la morfología de la de la Casa de Luaces, y en lo que respecta al interior, a Artiaga únicamente se le exigía abrir una chimenea francesa y una capilla con su altar. De todos modos, a finales de mayo de 1570 se modificaron algunos de los planteamientos iniciales. El Concejo prefirió abandonar la idea de erigir una arcada en la fachada meridional y se decantó por abrir dos ventanas "en el entresuelo", es decir, justo encima de la planta baja destinada a tiendas. Por aquel entonces la corporación municipal aprobó entregar al vizcaíno 65 ducados más de los 200 previstos $^{34}$.

33 REIGOSA MÉNDEZ, R.: "Las Casas de Consistorio de 1434 a 1587", Mondoñedo, n. ${ }^{\circ} 135,2018$, pp. 8-9. 34 AMM, Carp. 920, Libro de Actas (1566-1573), 1569 y 1570, s.f. LENCE-SANTAR Y GUITIÁN, E. Mondoñedo: El Santuario de los Remedios. Mondoñedo, César G Seco Romero, 1909 p. 68. PÉREZ

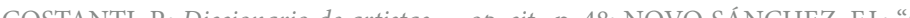
COsTANTH, D. Dicuonarió de artistas..., op. cit, p. (eds.): Arquitecturas desvanecidas. Memoria gráfica del patrimonio desaparecido en Galicia. Madrid, Abada, 2019, pp. 327-331 


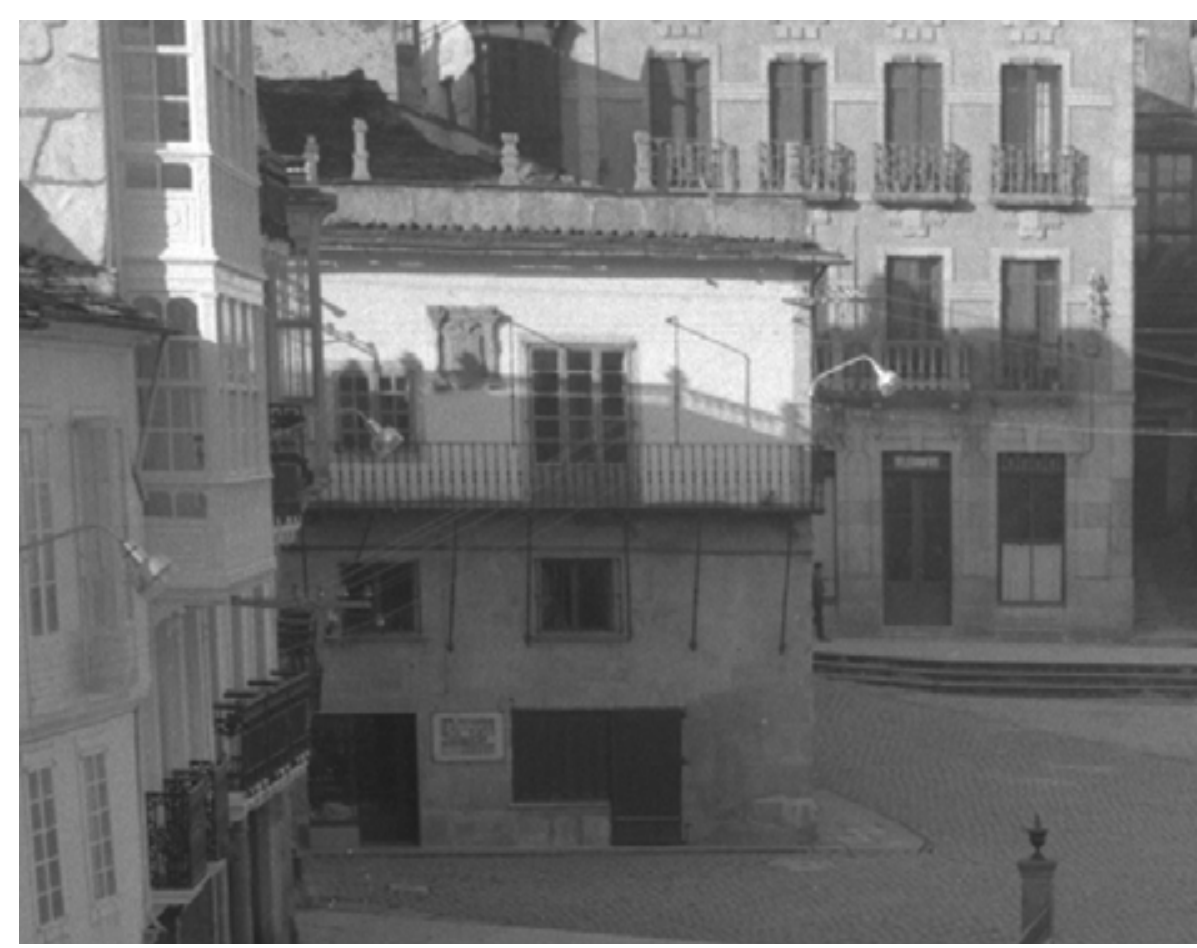

Fig. 3: Antigua Casa Consistorial de Mondoñedo. Pedro de Artiaga, 1569-1584. AHPL, Fondo J. José, sign. 02-02302. (Fotografía de Juan José Vivancos, ca.1950-1968)

Todo parece indicar que el grueso de la construcción se llevó a cabo en el primer lustro de la década de 1570. En este periodo las obras debieron avanzar a trompicones, pues en 1572 Mondoñedo sufrió un mortífero brote de peste y Artiaga aprovechó para trabajar en la Casa Consistorial de Lugo y para el Cabildo de dicha ciudad, como ya sabemos ${ }^{35}$. En la segunda mitad de 1574 el Ayuntamiento mindoniense mandó buscarlo hasta

35 Acerca de dicha peste véase AMM, Carp. 978, f. 50r; LENCE-SANTAR Y GUITIÁN, E.: "La muralla...," op. cit., p. 25

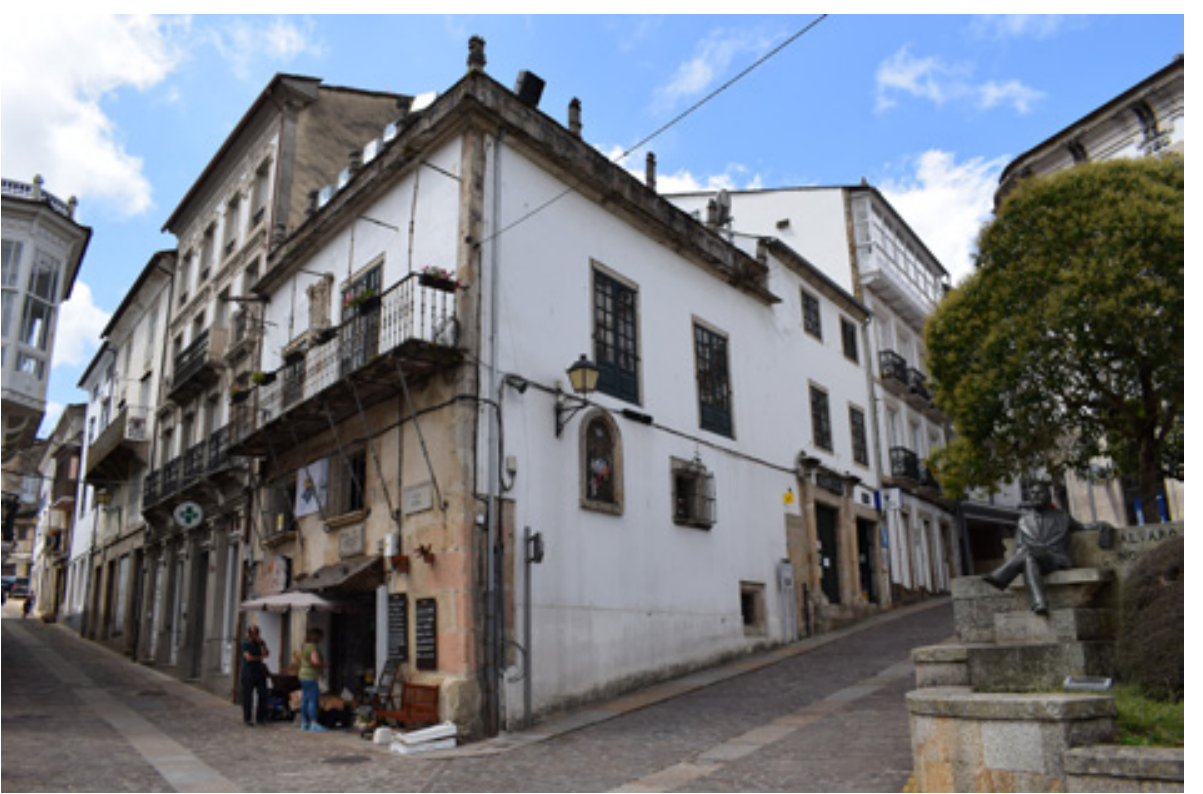

Fig. 4: Antigua Casa Consistorial de Mondoñedo en la actualidad

en dos ocasiones para que pusiese fin a las obras ${ }^{36}$. En agosto del año siguiente dispuso encarcelarlo por no dar las debidas fianzas de un contrato vinculado a la edificación del Consistorio, y además le ordenó hacer las armas imperiales "conforme a las estantes en la fuente desta çibdad", esto es, siguiendo el modelo de las presentes en la Fuente Vieja de 1548 -de ahí que sean idénticas ${ }^{-37}$. De esta manera, el Concejo volvía a inspirarse en otro monumento urbano de mediados de siglo para aplicar ciertos detalles de su morfología a la nueva Casa Consistorial, como ya sucediera con la Casa de Luaces. Entre 1576-1577 prevalecieron las obras de carpintería ${ }^{38}$. Y en 1578 se decidió alterar la composición de los

36 AMM, Carp. 921, Libro de Actas (1574-1586), ff. 44r, 53r-53v

37 Ibid. f. 88r. Acerca de la Fuente Vieja y sus modificaciones ulteriores véase GÓMEZ DARRIBA, J.: La ciudad de Mondoñedo..., op. cit., pp. 461-469.

38 AMM, Carp. 921, Libro de Actas (1574-1586), ff. 118r, 138r, 139v, 141v, 181r-181 
escudos. El Ayuntamiento quiso entonces homenajear al obispo Juan de Liermo por las citadas reformas de la Plazuela de la Fuente Vieja, que habían implicado la reconstrucción de una puerta de la muralla, del puentecillo inmediato, y de una alberca en la Rúa da Fonte. Por todo ello, el Concejo le ordenó a Artiaga ejecutar el blasón episcopal y disponerlo en el flanco izquierdo de la fachada meridional (fig. 5). También se encargaría de hacer el del Reino de Galicia y el imperial. El primero lo incrustaría en el otro extremo del frontis (fig. 6), mientras que las armas "enperiales" quedarían en medio ${ }^{39}$. En la actualidad solo esta permanecen in situ. Los otros escudos debieron retirarse de su emplazamiento original entre el último tercio del siglo XIX y principios del XX. No obstante, el 9 de marzo de 1934 el Ayuntamiento aprobó cedérselos al Museo Provincial de Lugo en calidad de depósito, institución que los mantiene expuestos en el claustro ${ }^{40}$.

Durante el segundo lustro de la década de 1570 y el primero de la consecutiva se llevaron cabo obras de menor importancia, señal inequívoca de que el edificio se estaba ultimando. En 1582 el cerrajero local Pedro López hizo las gárgolas de hierro, de las cuales solo se conserva una, adornada con motivos vegetales ${ }^{41}$. Se aprecian dos idénticas en un dibujo de la Plaza mindoniense que consideramos del primer tercio del siglo XIX, y en todo caso anterior a 1838 (fig. 7) ${ }^{42}$. En los años siguientes se efectuaron otras intervenciones, entre las que destacan el solado y blanqueado del inmueble, concluido en $1585^{43}$. De hecho debió de inaugurarse el año anterior, pues antes de que en 1871 se derribase parte del mismo, como luego veremos, existía una inscripción sobre la puerta del salón de plenos que rezaba lo siguiente: "Aqui dentro no ha lugar Pasion, temor ò interés. Solo el bien publico es El que aqui se ha de mirar. $1584^{\prime 44}$. Cabe señalar que desde este año muchas de las obras menores que se efectuaron en el edificio las llevaron a cabo Francisco de Artiaga "y sus conpaneros y

39 Ibid. f 226r. Consta que un pintor policromó y doró el escudo episcopal, operación que seguramente repitió en los demás, AMM Carp 978 f 55r. PÉREZ COSTANTI P. Diccionario de artistas. op. cit, pp. 48-49; LENCE-SANTAR Y GUITIÁN, E. "La muralla..." op. cit.,pp. 25-26.

40 AMM, Carp. 1057, Libro de Actas (1932-1936), p. 183. Al parecer el erudito Eduardo Lence-Santar los había encontrado en unas dependencias de la Casa Consistorial, VÁZQUEZ SEIJAS, M.: Fortalezas de Lugo y su Provincia. (Notas arqueológicas, históricas y genealógicas). Lugo, La Voz de la Verdad, 1959, t. 2, p. 212

41 AMM, Carp. 921, Libro de Actas (1574-1586), ff. 393r-393v.

42 Dicho dibujo se conserva en la Biblioteca Municipal de Mondoñedo [BMM]. Lo dio a conocer Reigosa Méndez, quien lo dató en torno a 1800, REIGOSA MÉNDEZ, R.: "La Muerte Negra en el Mondoñedo del s. XVI", Rudesindus, n. ${ }^{\circ} 12$, 2019, p. 248. Novo Sánchez, por su parte, lo ha creído de hacia 1820 , NOVO SÁNCHEZ, E.J.: "Antigua casa consistorial...” op. cit., p. 337 .

43 AMM, Carp. 921, Libro de Actas (1574-1586), 1584 y 1585 , s.

44 FLÓREZ, H.: España Sagrada. Theatro Geographico Historico de la Iglesia de España. Origen, divisiones, y limites de todas sus Provincias. Antiguedad, Traslaciones, y estado antiguo y presente de sus Sillas, con varias

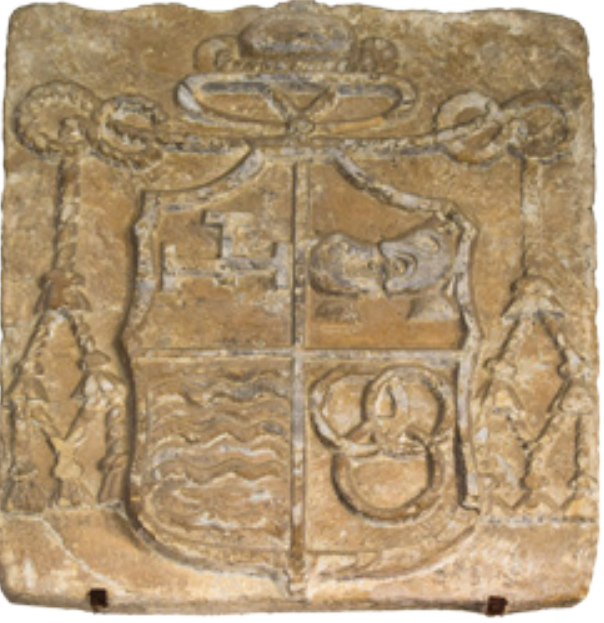

Fig. 5: Escudo episcopal de Juan de Liermo, Museo Provin cial de Lugo. Pedro de Artiaga, 1578-1579

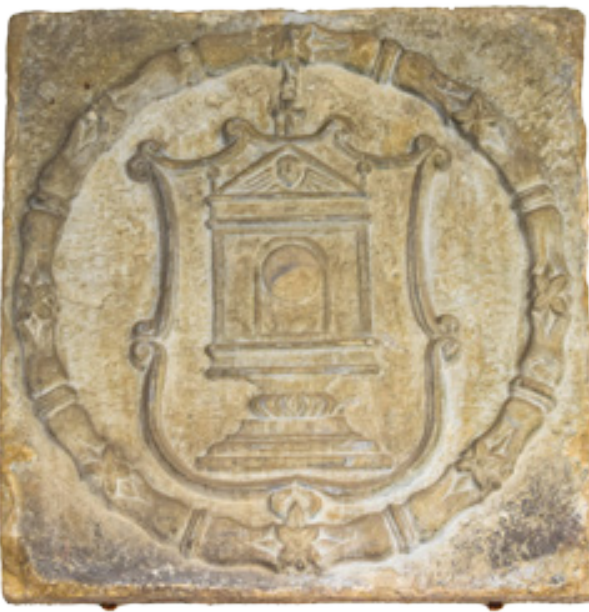

Fig. 6: Escudo del Reino de Galicia, Museo Provincial de Lugo. Pedro de Artiaga, 1578-1579 
ofiziales", lo cual significa que el pariente de Pedro de Artiaga cogió su testigo ${ }^{45}$. De hecho, el 1 de diciembre de 1587 el Ayuntamiento lo contrató junto con Martín y Rodrigo de Ris. "vizcaynos maest ${ }^{\circ 8}$ de canteria" como él, para que realizasen la escalera principal ${ }^{46}$.

Terminada la labor arquitectónica, el Concejo se preocupó por amueblar la capilla del flamante edificio. El 9 de febrero de 1587 contrató al escultor Juan de Villoldo, residente en Lugo, a fin de que hiciese un retablo para el recinto. El mueble contaría con un Crucifijo, una imagen de la Virgen y otra de san Sebastián. Las efigies tendrían una altura de 3,5 palmos. Villoldo cobraría 9 ducados por su realización y por el aporte de la madera ${ }^{47}$. El 14 de diciembre de dicho año la corporación municipal contrató al pintor Juan Llombart para que policromase las referidas imágenes. Además tendría que figurar un Monte Calvario y la ciudad de Jerusalén con su cielo y estrellas. La tipología del retablo podría ser la propia de un mueble relicario con batientes, pues también le ordenaron pintar a san Juan Bautista y a Santiago en la parte interna de las puertas. En la externa realizaría un jaspeado, motivo que aplicaría igualmente en la pared donde se situaba el retablo. Sin desechar la hipótesis anterior, este último dato induce a pensar que el retablo pudiera tratarse de una suerte de alacena con batientes. Sea como fuere, el 28 de marzo de 1588 la obra estaba concluida y a Llombart le faltaban por cobrar 14 ducados de los 28 en que había sido contratado. También entre finales de 1587 y principios de 1588 un entallador llamado Juan Fernández realizó un Calvario para dicha capilla, obra por la que fue remunerado con 8 reales $^{48}$.

Disertaciones criticas. Tomo XVIII. De las Iglesias Britoniense, y Dumiense, incluidas en la actual de Mondoñedo. Madrid, Antonio Marín, 1764, p. 249; FERNÁNDEZ VILLALBA, J.I.: Mondoñedo, regreso al pasado Recopilación de artículos publicados en diversos medios de comunicación por Don Eduardo Lence-Santar Guitián. Mondoñedo, Museo Catedralicio y Diocesano de Mondoñedo, 1999, t. 1, p. 99. Víctor de Silva fue pionero en advertir que dicho epígrafe había desaparecido "después de la Gloriosa" (1868), SILVA fue

45 El 30 de agosto de 1584 el Ayuntamiento contrató a Francisco de Artiaga por 42 ducados para que hiciese el losado, las escaleras, las puertas y el poyo o banco pétreo, AMM, Carp. 921, Libro de Actas (1574-1586), 1584 y 1585 , s.

46 AMM, Carp. 922, Libro de Actas (1586-1595), f. 41v.

47 Ibid., f. 22v; PÉREZ COSTANTI, P.: Diccionario de artistas..., op. cit., p. 570; FERNÁNDEZ VILLALBA, T.I.: Mondoñedo, regreso al pasado..., op. cit., t. 2, p. 20; NOVO SANCHEZ, F.J.: "La traza de los antiguos retablos mayores clasicistas de dos iglesias parroquiales de Lalín: Santiago de Catasós y San Xoán de Vilanoua" Cuadernos de Estudios Gollegos, t. 50, fasc. 116, 2003, p. 262. A meliados de marzo Villoho AM

48 Este escultor era iletrado y foráneo de Mondoñedo, ibid., ff. 45r, 50r, 58v. Novo Sánchez concluyó que el retablo debía de tener la tipología propia de los retablos relicario, NOVO SÁNCHEZ, F.J.: "Antigua casa consistorial..., op. cit., p. 332 .

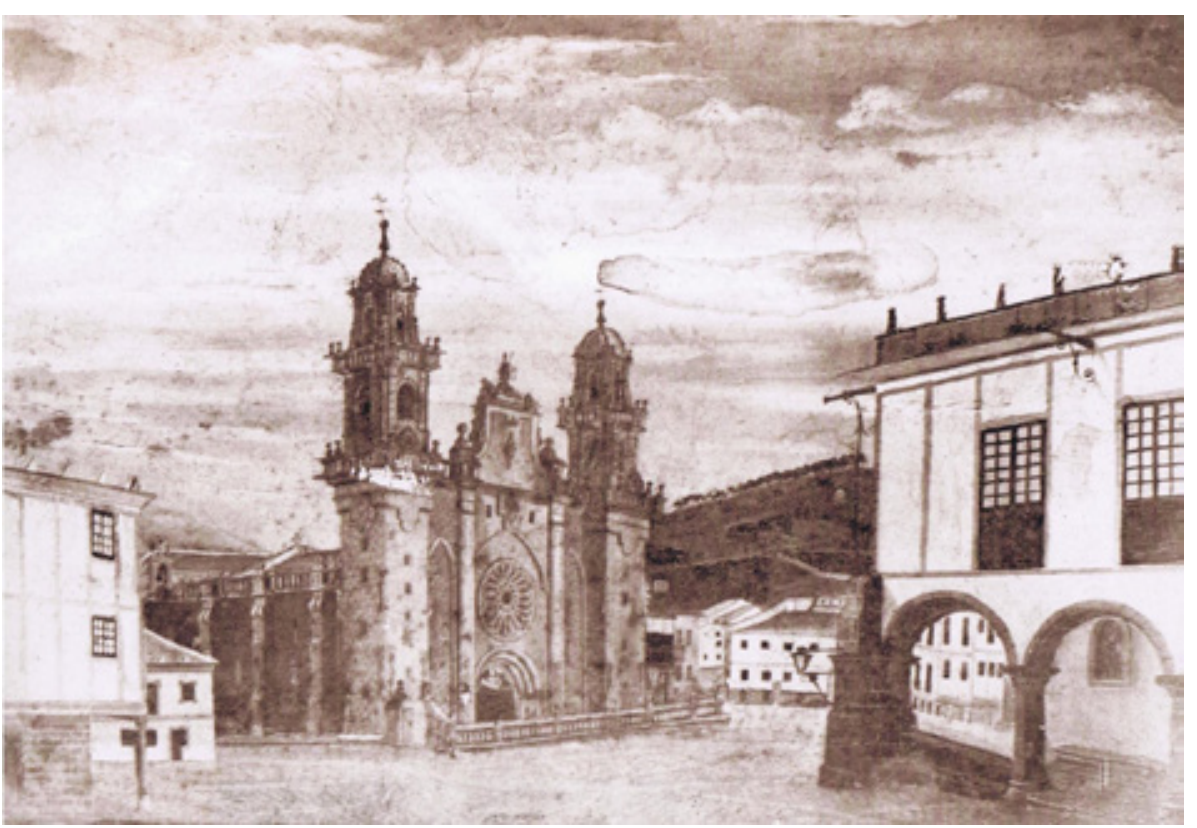

Fig. 7: Dibujo de la Plaza de Mondoñedo con el antiguo Consistorio a la derecha. Autor desconocido, ca.1800-1830 BMM, sin sign. (Fotografía de Roberto Reigosa Méndez)

A lo largo del siglo XVII la Casa Consistorial sufrió varias reformas. En 1611 el Ayuntamiento contrató al maestro trasmerano Pedro de Morlote para que ejecutase distintos arreglos ${ }^{49}$; en 1626 hizo lo propio con Pedro de Palacios a fin de levantar una pared en el exterior ${ }^{50}$; y en 1678 reconoció que el edificio estaba arruinado, y que, aparte de adecentarlo, convendría realizar "un par de alcobas a la entrada del quarto de la coçina" ${ }^{\text {"51 }}$. Esta lamentable situación se agravó con el paso de los años. En 1723 el arquitecto asturiano José Martínez Celiz y su colega Sebastián Díaz Ribadeneira manifestaron que sería necesario demolerlo y

49 AMM, Carp. 924, Libro de Actas (1609-1622), ff. 87v-88v.

50 Archivo Histórico Provincial de Lugo [AHPL], Protocolos Notariales, Mondoñedo, Domingo Rodríguez Bermúdez, leg. 8376-2, ff. 107r-108r.

1 AMM, Carp. 933, Libro de Actas (1676-1680), 1678, ff. 45v-46r 
hacerlo de nueva planta conforme a una traza del primero. El nuevo proyecto destacaba por la pretensión de levantar dos fachadas con arquerías, balcones volados con balaustres de hierro o canalones con gárgolas en las esquinas. En este sentido, parece como si se quisiera emular el edificio quinientista de Artiaga. De todos modos, dicha obra nunca se materializó ${ }^{52}$. Aun así la ruina alcanzó tal extremo que, en 1749 se clausuró y apuntalós3 En 1751 el maestro cantero Bartolomé Ramos y el carpintero José de Cora analizaron su estado. A raíz de su peritaje se aprobó cegar ciertos vanos, abrir otros nuevos, y realizar una balconada de hierro que recorriese la fachada meridional. El remate de las obras se adjudicó por 2800 reales al propio Ramos, a su colega Esteban Fernández Villanueva y a dos carpinteros ${ }^{54}$. En 1771 también se examinaron los reparos de diversa índole que urgía acometer en el edificio y en sus bienes muebles. En la visita pericial participaron el maestro de obras José Carballeda y el carpintero Antonio García y Romero, quienes consideraron necesario renovar la arcada ${ }^{55}$. El 10 de marzo de 1778 se celebró el remate de esta obra en el salón de plenos. La tomó el maestro Gregorio de Otero, quien hubo de llevarla a cabo a lo largo de aquel año, pues en febrero de 1779 ya la había concluido y su colega Luis Fernández Bouso realizaba la tasación de lo ejecutado ${ }^{56}$. Todavía en 1790 se estudió intervenir en las cubiertas para no agravar la ruina general del inmueble ${ }^{57}$. Y en 1799 examinó su estado el arquitecto académico Miguel Ángel de Uría, quien planteó un conjunto de reformas que no se materializaron ${ }^{58}$.

El siglo XIX resultó muy dañino para la fábrica original del Consistorio, pero al menos legó una documentación gráfica de gran valía para entender su distribución espacial y para tener una idea más clara de cómo era su alzado por el flanco de levante. Esto último lo sabemos gracias al dibujo de la Plaza ya citado, a una planta del edificio realizada en 1813 por el mencionado Miguel Ángel de Uría ${ }^{59}$, y a una planimetría urbana delineada en 1865 por

52 AMM, Carp. 943, Libro de Actas (1721-1725), 1723, 1724, 1725, s.f.; Carp. 1627, s.f.; NOVO SÁNCHEZ, F...: "Antigua casa consistorial..., op. cit., pp. 332-334.

53 AMM, Carp. 948, Libro de Actas (1746-1750), 1749, 1750, s.f.

54 AMM, Carp. 949, Libro de Actas (1751-1755), 1751, ff. 8r, 10r-10v, 20r-21r, 24r-27r, 43r-44r, 71r-77r $100 \mathrm{r}-100 \mathrm{v}$.

55 El precio estimado para la obra lo ratificaron en 1775 el propio Carballeda y el arquitecto Ignacio Es tévez tras un nuevo reconocimiento pericial, AMM, Carp. 2710, ff. 1r-8r ( $1^{a}$ foliación) y 9r-13r (2 foliación); NOVO SÁNCHEZ, F.J.: “Antigua casa consistorial...”, op. cit., pp. 334-338.

6 AMM Carp. 2710, s.f. NOVO SÁNCHEZ, EJ.: "Antigua casa consistorial..." op. cit., p. 340.

57 AMM, Carp. 953, Libro de Actas (1781-1790), s.f.

8 AMM, Carp. 955, Libro de Actas (1797-1800), 1799 y 1800, s.f.

59 AMM, Carp. 2250-5, s.f.
Rafael de Luque y Lubián ${ }^{60}$ (fig. 8). Uría planteó la redistribución de las estancias interiores por un precio no inferior a 8000 reales $^{61}$. Pero lo verdaderamente interesante es que trazó el referido plano, lo cual no significa que la localización y el tamaño de las habitaciones fuese exactamente igual que en el edificio construido por Artiaga. En la planta baja había una sala para celebrar los sorteos, otra para el cuerpo de guardia, y, al fondo, una escalera que daba al patio y otra que subía al piso principal. Esta llegaba a una antesala por la cual se podía acceder o bien a la cocina, sita en un último piso tras la ascensión de otras escaleras, o bien al salón de plenos. Este era la pieza más amplia de todo el edificio. Lo iluminaban cuatro vanos y se comunicaba con el archivo y la capilla, cuyo altar se orientaba al norte.

A lo largo del siglo XIX el gobierno municipal intentó en varias ocasiones eliminar la arcada que daba hacia el Cantón Pequeño, aunque sin éxito. Hasta que a finales de 1869 un informe del arquitecto provincial declaró el edificio en estado de ruina. La razón principal eran los considerables daños que presentaban los machones y arcos del soportal. Según su criterio, la mejor solución sería demoler la parte afectada, lo cual se llevó a efecto entre abril y mayo de $1871^{62}$. El plano de Uría y el citado dibujo decimonónico demuestran que los pilares de la arcada eran ochavados ${ }^{63}$. El formato de los capiteles no guarda relación con los que conserva el Consistorio en su antigua portada. Estos presentan un orden toscano poco canónico y lo más probable es que no correspondan a la fábrica quinientista. Lo cierto es que han sido tantas las reformas experimentadas por este edificio desde que se construyera en el último tercio del XVI que resulta complejo indicar con seguridad qué parte se debe a dicha centuria, cuál al XVIII, etc. En la actualidad el inmueble alberga la Biblioteca y Oficina de Turismo Municipales, y en la planta baja que mira a la Praza da Catedral un espacio comercial y otro hostelero. Del primitivo Consistorio se conserva si acaso la localización de su portada principal, aunque, como se dijo, quizá su arco adintelado y sus columnas embebidas no correspondan al hacer de Artiaga. Sí pertenecen al edificio primigenio los pináculos con forma de candeleros que coronan el antepecho del primer piso; el escudo imperial; la única gárgola férrea que se conserva; quizás las ventanas del

60 AMM, Carp. 1628, s.f.

61 PÉREZ RODRÍGUEZ, F.: "Noticias sobre tres arquitectos de la Ilustración gallega: Melchor de Prado y Mariño, Felipe Gianzo y Miguel Ángel de Uría", Brigantium, n. ${ }^{\circ}$ 14, 2003, pp. 335, 339; NOVO SÁNCHEZ, EJ: "Antigua casa consistorial. ", op, cit, pp. 340-343.

62 AMM, Carp. 967, Libro de Actas (1861-1870), acta municipal del 25 de noviembre de 1869, s.f.; Carp. 968, Libro de Actas (1871-1880), actas municipales del 3 de abril y del 22 de mayo de 1871, s.f.

63 Sin embargo el plano de Rafael de Luque (1865) presenta unos pilares hexagonales. Su esquematismo in trínseco hace que la referida vista decimonónica y la planta de Uría resulten fuentes gráficas más fiables. 


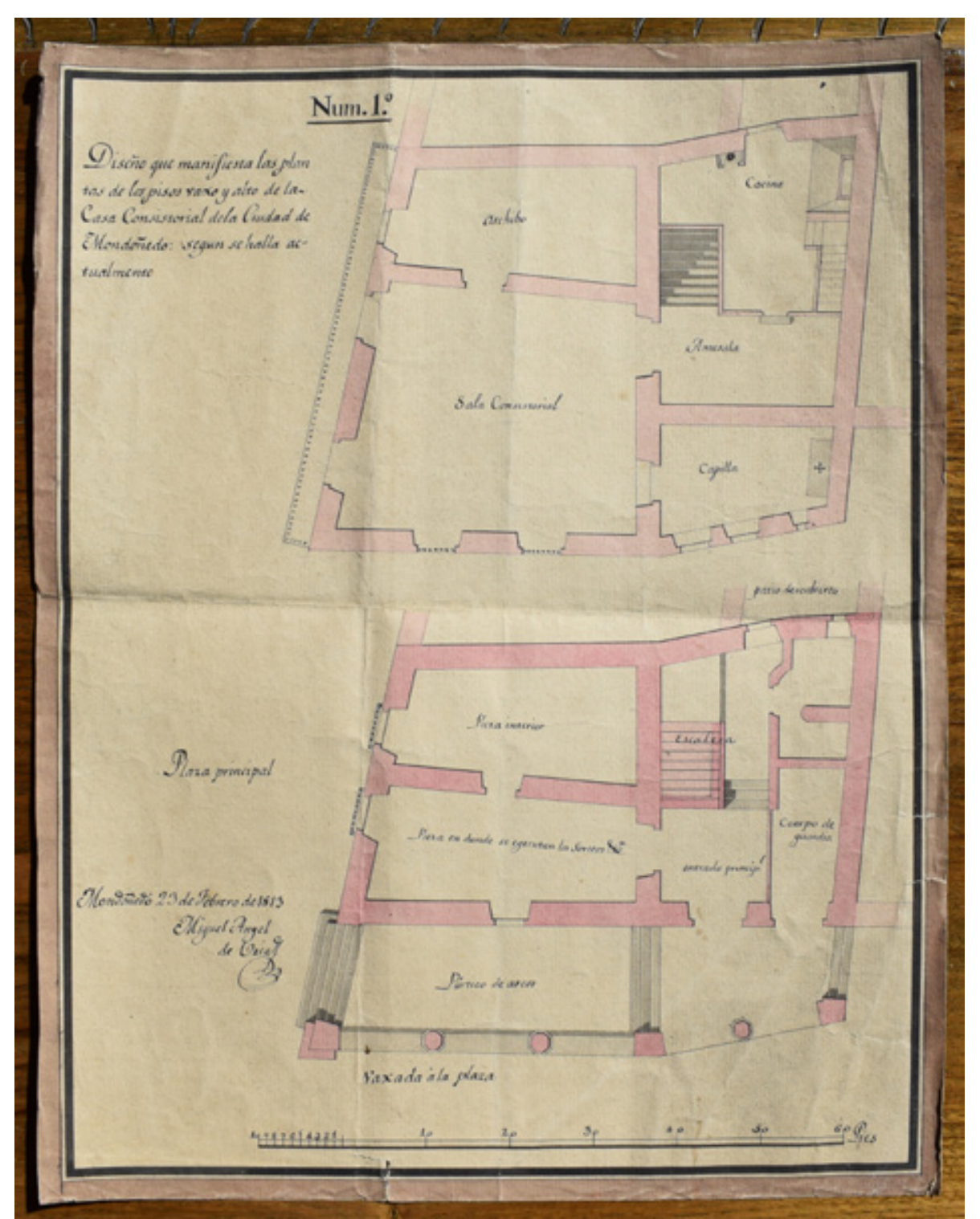

Fig. 8: Planta de la antigua Casa Consistorial de Mondoñedo. Miguel Ángel de Uría, 1813. AMM, Carp. 2250-5, s.f. entresuelo y los tableros de la planta baja que miran a la Plaza; así como el vano dispuesto junto a la hornacina de san Roque, cuya escultura es de avanzado el siglo XVIII. De todos modos, respecto a las tres ventanas citadas y a los tableros, mantenemos ciertas reservas puesto que pudieron sufrir alteraciones ${ }^{64}$.

Por último, cabe destacar que las funciones intrínsecas a un inmueble concejil coincidieron con otras de tipo comercial, algo que también sucedió en la Casa Consistorial lucense y en otras muchas de la España del Antiguo Régimen. Dado que la hacienda municipal de Mondoñedo solía estar bajo mínimos, la recepción de cualquier ganancia siempre era bienvenida. En este sentido el Ayuntamiento se benefició de las tiendas que existían en la planta baja. Previa la construcción del Consistorio, el mercero Juan Bernáldez poseía dos puestos en aquel solar ${ }^{65}$, cuya propiedad mantuvo incluso estando el edificio parcialmente levantado ${ }^{66}$. El Concejo compró estas tiendas a finales del siglo XVI o principios del XVII con objeto de arrendarlas, y durante la primera mitad del seiscientos fueron sendas mercerías. El precio de su alquiler oscilaba en torno a 5 o 6 ducados anuales. Una daba hacia la Plaza y otra al Cantón Pequeño ${ }^{67}$. Tal era la pretensión del Ayuntamiento por ganar arrendatarios que, en 1622 , convirtió en vivienda un cuarto situado en el ángulo de la planta baja ${ }^{68}$. Por último, las panaderas de Mondoñedo también resultaron un elemento consustancial al edificio concejil, pues antes de que se construyese ya vendían el pan junto al solar donde se levantó. Una vez concluido se establecieron durante toda la Edad Moderna bajo el soportal de levante, de ahí que la calle que nacía junto a dicha arquería, conocida desde el Medievo como Rúa Nova, adquiriese el apelativo de Calle de las Panaderas ${ }^{69}$.

64 Novo Sánchez ha emitido recientemente su opinión acerca de lo que se conserva del Consistorio primitvo, NOVO SÁNCHEZ, F.J.: "Antigua casa consistorial..., op. cit., p. 345. Con anterioridad Vila Jato indicó que del edificio primigenio solo subsistía el escudo imperial, VILA JATO, M.D.: "La actividad artística en la provincia de Mondoñedo durante el Renacimiento", Estudios Mindonienses, n. ${ }^{15}$ 1599, p. 461.

65 NOVO SÁNCHEZ, F.J.: "Antigua casa consistorial..., op. cit., p. 328.

66 En 1576 declaró poseer "tiendas [...] en la plaza pública de la Ciudad, debaxo de las casas del ConsistoEn 1576 declaró poseer "tiendas [...] en la plaza pública de la Ciudad, debaxo
rio", CAL PARDO, E.: Mondoñedo -Catedral, Ciudad..., op. cit., pp. 334-335.

67 AHPL, Protocolos Notariales, Mondoñedo, Domingo Rodríguez Bermúdez, leg. 7192-4, ff. 70r-70v y leg. 8376-1, f. 105r. De la última existe una referencia de 1650 indicando que se halla "en la caueça de la plaça desta dha ciud debaxo de las casas de ayuntamy della ques la questa a la p ${ }^{\text {te }}$ de la plaça de las panaderas", AHPL, Protocolos Notariales, Mondoñedo, Juan de Legaspe, leg. 8257-5, ff. 257r-258v; Domingo López Traveso, leg. 6865-3, f. 84r.

68 Se le cita de la siguiente manera: "un quarto bajo que por una parte tiene ventanas hacia la plaça mayor desta ciudad y por otra parte una bentana hacia la panaderia della", AHPL, Protocolos Notariales, Mondoñedo, Domingo Rodríguez Bermúdez, leg. 8375-1, ff. 191r-192r

69 GÓMEZ DARRIBA, J.: La ciudad de Mondoñedo..., op. cit., pp. 116-117, 141-142. 
Respecto a la Casa Consistorial de Lugo cabe destacar que en octubre de 1570 el Rea Consejo le concedió a la ciudad el derecho a realizar un repartimiento que sirviese para financiar distintas obras públicas, destacando entre todas ellas la construcción de una Casa de Concejo. El inmueble se levantaría en el sector oriental de la Plaza de las Cortiñas de San Román, en un solar ocupado por las llamadas Casas de la Feria, en cuyos bajos había tiendas y artesanos. Dicha parcela corresponde en la actualidad al lugar donde se erige el edificio dieciochesco del Ayuntamiento, en la Plaza Mayor. En 1570 el terreno pertenecía a la dignidad episcopal, pero el obispo Fernando de Vellosillo lo permutó al Concejo. La obra de la Casa Consistorial se contrató a Pedro de Artiaga, quien cobraría por su trabajo 1200 ducados sin contar los materiales y el subsiguiente acarreo ${ }^{70}$. El vizcaíno presentó las trazas a la corporación municipal el 16 de agosto de 1571, esto es, año y medio después de haber diseñado el Consistorio mindoniense, y recibió 4 ducados por la ejecución de las mismas (figs. 9 y 10$)^{71}$. El edificio lo concluyó en esa misma década ${ }^{72}$. No cabe duda de que el haber delineado e iniciado las obras del Ayuntamiento de Mondoñedo resultó un facto determinante para que el gobierno municipal de Lugo le confiase hacer lo propio. Si bien en Mondoñedo se conserva buena parte del inmueble original pero no las trazas primigenias, en Lugo sucede todo lo contrario, pues solo han sobrevivido los planos, dado que entre 1735-1738 el arquitecto compostelano Lucas Ferro Caaveiro diseñó y construyó el actual Ayuntamiento $^{73}$. Interpretar las trazas de Artiaga no resulta del todo sencillo por su carácter esquemático y porque tampoco se conservan las cláusulas de la obra. Su ejecución denota que no era un excepcional dibujante, y asimismo que planteó un edificio relativamente similar al mindoniense. En esta ocasión gozaba de un solar mucho más amplio donde erigirlo. El maestro definió el inmueble en base a una planta cuadrangular vertebrada por un patio central. La fachada mediría 23,4 $\mathrm{m}$ de largo y 12 de alto, mientras que los frentes laterales alcanzarían los $16,7 \mathrm{~m}$. El patio tendría $9 \mathrm{~m}^{2}$. Cada panda se articularía con tres

70 LÓPEZ ACUÑA, A.: "Las Casas Consistoriales..., op. cit., pp. 56-57. A lo largo del siglo XVI el Concejo se había reunido en diferentes sitios de la ciudad, destacando entre todos una torre de la muralla ABEL VILELA, A. DE: "Arquitectura manierista en Lugo. Las Casas Consistoriales de Pedro de Artiaga", Abrente, n.o 26, 1994, pp. 161-163, 165-167; ABEL VILELA, A. DE: Urbanismo y arquitectura..., op. cit., pp. 38-44.

71 GOY DIZ, A.: "Proyecto para las Casas..., op. cit., p. 524. Se custodian en el Archivo del Museo Provin cial de Lugo [AMPL], ES AMPL-28-3.81-1.

72 ABEL VILELA, A. DE: “Arquitectura manierista...," op. cit., pp. 169-170.

73 Acerca de este monumento dieciochesco véase LOPEZ ACUÑA, A.: "Las Casas Consistoriales..., op. cit., pp. 60-62; VILA JATO, M.D.: Lugo Barroco. Diputación Provincial de Lugo, Lugo, 1989, pp. 71-73, ABEL VILELA, A. DE: Urbanismo y arquitectura..., op. cit., pp. 180-186; ABEL VILELA, A. DE: "A etapa lucense de Lucas Antonio Ferro Caaveiro", Lucensia, vol. 28, n. ${ }^{\circ}$ 55, 2017, pp. 119-125.

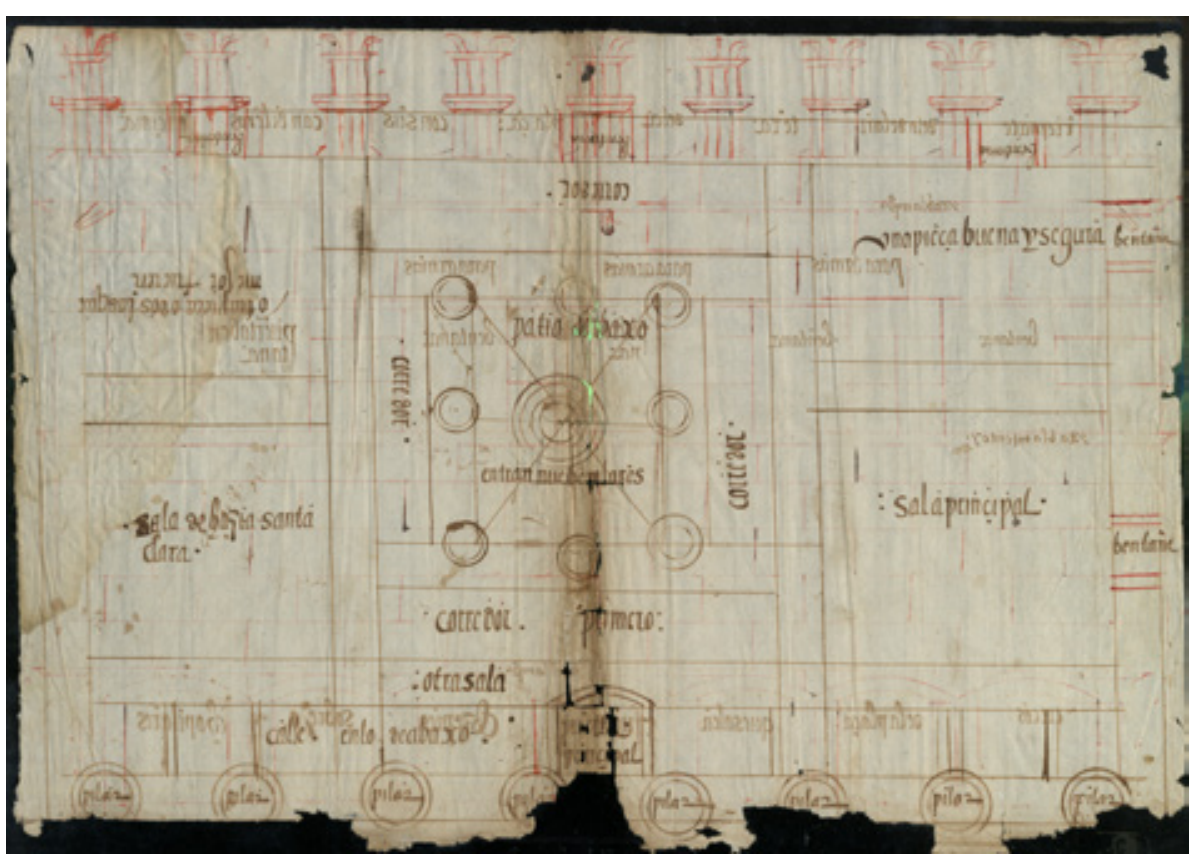

g. 9: Planta de la antigua Casa Consistorial de Lugo. Pedro de Artiaga, 1570-1571. AMPL, ES AMPL-28-3.81-1

columnas, y el corredor del primer piso comunicaría con todas las estancias principales ${ }^{74}$. En la planta baja se situarían las tiendas -al igual que en Mondoñedo-, así como la alhóndiga y la pescadería. Mientras que en el piso principal las salas de mayor notoriedad, inclusive el salón de plenos, que miraría hacia la Plaza Mayor. En el flanco opuesto se abriría una solana al jardín trasero. La fachada principal contaría en su piso bajo con un soportal formado por ocho pilares cilíndricos y siete arcos escarzanos. Esta arcada cobijaría la puerta principal con un arco de igual morfología. Sobre la arquería se auparía un lienzo compuesto por cinco hiladas de sillares. Encima se abrirían tres ventanas y dos puertas ventana. Sobre los vanos centrales se encastrarían tres escudos de armas. Aunque el plano no revela cuáles, suponemos que el de la Ciudad, o en todo caso el del Reino de Galicia

74 Los datos de las medidas los aportó LÓPEZ ACUÑA, A.: "Las Casas Consistoriales...", op. cit., p. 57 


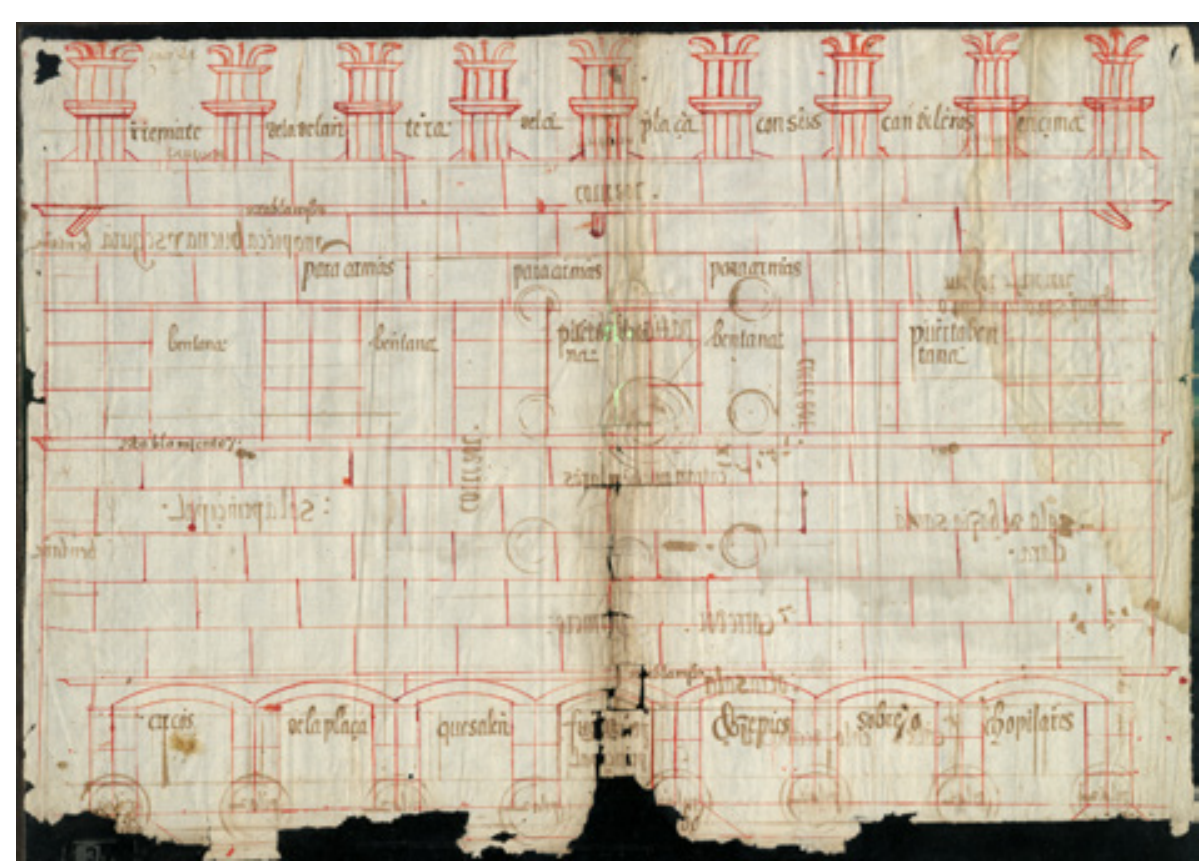

Fig. 10: Alzado de la fachada de la antigua Casa Consistorial de Lugo. Pedro de Artiaga, 1570-1571. AMPL, ES AMPL-28-3.81-1

-como ocurría en Mondoñedo-; el real, por ser el Real Consejo el organismo que aprobó el sistema de financiación del edificio; y quizás el episcopal de Fernando de Vellosillo, prelado que había permutado al Ayuntamiento el solar donde se levantó el inmueble. El frontis lo culminaría una cornisa con tres gárgolas y un antepecho coronado por nueve pináculos con forma de "candileros", tal y como indica la traza. Estos son muy semejantes a los que coronan el Consistorio mindoniense $\mathrm{e}^{75}$.

75 Cabe señalar que las trazas de Pedro de Artiaga también han sido analizadas por Novo Sánchez en un par de fichas integradas en VIGO TRASANCOS, A. (Dir.): Planos y dibujos de arquitectura y urbanismo. Galicia en los Siglos XVI y XVII. Santiago de Compostela, Consello Galego de Colexios de Aparexadores e Arquitectos Técnicos, 2003, pp. 184, 186 .
Las Casas de Ayuntamiento de Lugo y Mondoñedo constituyeron la sede legítima del gobierno civil y el edificio más representativo de su poder en ambas ciudades. Su privilegiado emplazamiento y su arquitectura dignificaron al gobierno municipal y por ende a la urbe. Resultaron dos inmuebles funcionales en tanto en cuanto supusieron el lugar donde se desarrolló la res publica de cada ciudad, actividad que estuvo en todo momento subyugada a la Corona, de ahí que no se deba subestimar la importancia de la figura del corregidor en ambas capitales del Reino de Galicia, y, en relación a ello, la presencia de las armas imperiales en la fachada mindoniense y muy probablemente en la lucense. Por otra parte, la relevancia arquitectónica de ambos inmuebles también se manifestó en el empleo de los materiales, pues todos sus frentes se revistieron con sillares de cantería. El carácter recio y adusto de estos muros, carentes en su piso principal de cualquier elemento articulador $\mathrm{u}$ ornamental, se complementó con la presencia de soportales en la planta baja. Un elemento dialogante con el entorno urbano inmediato, máxime cuando cumplían una función comercial. A este aperturismo hacia la ciudad también contribuyeron los balcones y puertas ventanas, elementos idóneos para que las corporaciones municipales contemplasen las procesiones, los desfiles militares o las corridas de toros que se celebraban en ambas plazas, y, por supuesto, para que los alcaldes y regidores resultasen vistos desde el foro público. En estos edificios apenas hubo lugar para el adorno. Sus lienzos de cantería se timbraron con los blasones representativos de los poderes que de algún modo tenían competencias en el Ayuntamiento o que habían contribuido a financiar las Casas Consistoriales y otras infraestructuras urbanas. La única nota decorativa la pusieron los pináculos con forma de candelero que culminaron las fachadas. Estos pudieron jugar un rol celebrativo habida cuenta de que en ciertos festejos el remate de ambos edificios se rodeaba de luminarias, rasgo muy típico de la fiesta en la España del Antiguo Régimen ${ }^{76}$.

Por último, cabe destacar que Pedro de Artiaga concibió dos edificios que tenían que adaptarse a espacios amplios pero insertos a su vez en un solar preestablecido. Generó sendos bloques de planta cuadrangular con un pequeño patio interno en el caso de Lugo, y los abrió a las plazas por medio de arcadas. Tipológicamente se vinculan con múltiples consistorios levantados en la España del XVI, los cuales presidían las plazas más importantes de las localidades, tenían tiendas y soportales en la planta baja, y en cuyo piso superior se desarrollaba la vida municipal ${ }^{77}$. A la vista de su morfología no podemos

76 Sobre la presencia de luminarias en las fachadas de ambos edificios véase ABEL VILELA, A. DE: Ur banismo y arquitectura..., op. cit., pp. 215-216; GÓMEZ DARRIBA, J.: La ciudad de Mondoñedo..., op. cit., pp. 120-121.

77 GOY DIZ, A.: "Proyecto para las Casas...", op. cit., p. 524. 
establecer paralelismos significativos con otras casas de concejo levantadas en el quinientos en las antiguas diócesis de Calahorra, Pamplona y Tudela ${ }^{78}$. Ni tampoco hacer lo propio con las erigidas en otras capitales gallegas ${ }^{79}$. De todos modos, hay quien ha advertido grandes semejanzas entre el edificio consistorial lucense y el de Sigüenza (Guadalajara) o Alarcón (Cuenca) ${ }^{80}$

\section{LA FIGURA DE FRANCISCO DE ARTIAGA}

La última noticia que se tiene de Pedro de Artiaga en Mondoñedo data de marzo de $1587^{81}$ Ignoramos si entonces se mudó a otro sitio o falleció, pero a partir de 1584 Francisco de Artiaga fue el encargado de asumir en la urbe el mismo papel de maestro de obras que había desempeñado su supuesto pariente. Como dijimos, el Ayuntamiento lo contrató en aquel año para que realizase pequeñas obras en la Casa Consistorial, y, en 1587, volvió a hacerlo para que junto con Martín y Rodrigo de Ris hiciese la escalera principal de dicho edificio. Entonces el Concejo también les exigió empedrar algunas calles y ciertas zonas de la Plaza Pública, caso de los soportales o de las inmediaciones de la Cárcel Eclesiástica ${ }^{82}$. Escasos años más tarde les confió más obras en las inmediaciones del núcleo urbano, concretamente la construcción de dos puentecillos de pizarra que sustituyesen a los existentes de madera. En 1592 contrató a Artiaga y a Martín de Ris para que realizasen el de Ruzos, hoy conocido como Puente del Pasatiempo ${ }^{83}$. Y al año siguiente se concertó con ellos para que erigiesen el de San Lázaro. En esta ocasión pujaron por el remate de la obra frente a Juan Rodríguez, un

78 Sobre este particular véase Casas consistoriales de Navarra. Pamplona, Gobierno de Navarra, 1998 MINTEGI LUENGO, Ne Casas consistoriales de las villas de Bizkaio. Billo bao, 2009

79 GALLEGO DOMÍNGUEZ, O.: "Las casas consistoriales de la ciudad de Ourense", Boletín Auriense, $\mathrm{n}$. 10, 1980, pp. 107-117; TAÍN GUZMÁN, M.: As antigas Casas do Concello de Santiago de Compostela. A sede da praza de Cervantes (1689-1787). Santiago de Compostela, Concello de Santiago de Compostela, Universidade de Santiago de Compostela, 2003; FERNANDEZ GASALLA, L., GOY DIZ, A.: "Las casa consistoriales de Santiago de Compostela en los siglos XVI y XVII", Sémata, n. ${ }^{\circ} 15,2003$, pp. 545-586.

80 GORDO PELÁEZ, L.J.: Equipamientos y edificios..., op. cit., p. 192.

81 AMM, Carp. 922, Libro de Actas (1586-1595), ff. 25r-25y

82 De los tres canteros citados, solo Francisco y Rodrigo tomaron las obras. Lo hicieron a razón de 2,5 reales por braza, Ibid., ff. $36 \mathrm{v}, 39 \mathrm{r}, 40 \mathrm{v}-40 \mathrm{r}$

83 Ibid., ff. 176r-176v. cantero local al que desmerecieron acusándole de carecer de pericia en construcciones de esta índole ${ }^{84}$. Paradójicamente ni Artiaga ni su compañero debían ser muy duchos en esta materia, pues la elección de la pizarra se demostró ineficaz habida cuenta de que ambos puentes sufrieron graves daños a inicios del siglo XVII, de ahí que el de San Lázaro tuviera que hacerlo ex novo Pedro de Morlote en $1618^{85}$.

La última obra que se le conoce a Francisco de Artiaga en Mondoñedo se trata de una casa levantada junto al santuario de Nuestra Señora de los Remedios, pero, al igual que las anteriores, tampoco se conserva. Ignoramos qué función cumplía aquella vivienda para que fuese costeada con los fondos del santuario. Dado el tiempo que se tardó en construirla y la importancia que se le dio a la obra no parece que se tratase de la casa de la ermitaña. Tampoco se estima probable que fuese un hospital para alojar peregrinos, porque este se levantó a partir de 1612. Sea como fuere, entre 1593-1595 trabajaron en ella el portugués Fernando Yanes y Juan Leal "padre" ${ }^{\text {". En }} 1595$ constan varios pagos a los canteros "vizcaynos" que operaron en la vivienda, y es un hecho que el 1 de noviembre Francisco de Artiaga recibió el finiquito de la misma. Hubo de ser él quien dirigiese a la cuadrilla de pedreros en la cual se encontraba un tal Jácome Fernández, de quien no nos ha llegado su rúbrica pese a que sabía firmar ${ }^{87}$. Con lo cual, no se puede precisar si se trataba del homónimo personaje que durante la década de 1610 ocuparía el puesto de maestro de obras de la catedral de Santiago de Compostela. Lo más probable es que no. Como se indicó al inicio de este trabajo, la última noticia conocida acerca de Francisco de Artiaga data de principios del siglo XVII, época en la que trabajaba en la localidad cántabra de Noja.

84 La obra la llevaron a cabo entre mayo y agosto de 1593. Cobraron por ella 47 ducados, ibid., ff. $205 \mathrm{v}-206 \mathrm{v}, 208 \mathrm{v}$.

85 Sobre la inminente ruina que sufrieron estos puentes véase GÓMEZ DARRIBA, J.: "De piedra, arcos agua. La construcción de puentes en el noreste de Galicia durante la Edad Moderna", Santander. Estudios de Patrimonio, n. ${ }^{\circ}$ 3, 2020, pp. 241-243, 246-250.

86 Archivo Histórico Nacional [AHN] Clero Secular Regular, leg. 6373, ff. 22r, 35r, 80r-82r, 83r, 84v $85 \mathrm{v}-87 \mathrm{v}, 88 \mathrm{v}, 96 \mathrm{v}-100 \mathrm{r}, 125 \mathrm{r}-125 \mathrm{v}$

87 Ibid., ff. 86r, 87 


\section{CONCLUSIONES}

Pedro y Francisco de Artiaga fueron dos maestros de cantería de origen vasco que en la segunda mitad del siglo XVI encontraron en las antiguas provincias de Lugo y Mondoñedo el lugar idóneo para desarrollar su oficio al amparo fundamentalmente de las instituciones públicas y de la Iglesia local. Su migración al Reino de Galicia por motivos laborales y su prolongada estancia en aquella región debe contextualizarse en el fenómeno de expansión que, por aquel entonces, centenares de vascos y cántabros dedicados al arte de la arquitectura y la cantería protagonizaron por todo el territorio peninsular. En el caso gallego, la llegada de artistas montañeses y más en concreto de trasmeranos resultó un acontecimiento extraordinario, tanto en lo cuantitativo como en lo cualitativo si tenemos en cuenta la relevancia de los proyectos que diseñaron y acometieron. Sin embargo, la presencia de artistas vascos fue verdaderamente excepcional. Sin lugar a dudas, en la capital provincial y episcopal de Mondoñedo los Artiaga resultaron los maestros de cantería más destacados del momento. En Lugo, sin embargo, Pedro tuvo muchas más dificultades a la hora de adjudicarse obras, puesto que hubo de competir con arquitectos tan destacados como los trasmeranos Pedro y Gonzalo de la Bárcena, Gaspar de Arce, etc. Pese a que apenas se conservan obras de estos vizcaínos, es un hecho que sabían leer y escribir, que estaban acostumbrados a ejercer de aparejadores, y, al menos en el caso de Pedro, que tenía la capacidad para realizar trazas y dar condiciones, aunque luego tuviera que tomarlas él mismo para poder vivir de su oficio. Lo poco que nos ha llegado de su actividad artística, bien sea por medio de fábricas arquitectónicas, bien a través de diseños, denota un claro apego a soluciones propias de la primera mitad del siglo XVI cuando no de fines del XV, y por supuesto un desinterés por la tratadística coetánea y por la arquitectura clásica en general. De ahí el empleo de basas poligonales, arcos escarzanos, y la inclusión de algún que otro elemento ornamental a la "romana". La formación de ambos hubo de estar muy vinculada al taller, o, dicho de otra forma, hubo de ser más práctica que teórica. A la vista de su trayectoria, soslayada por la historiografía hasta la fecha, queda claro que resultaron de los pocos maestros de obras vascos presentes en la Galicia de la segunda mitad del siglo XVI. Y también que fueron capaces de ganarse la confianza de una importante clientela artística, lo cual les llevó a asentarse durante largos periodos en el noroeste peninsular. 


\section{BIBLIOGRAFÍA}

ABEL VILELA, A. DE: "Arquitectura manierista en Lugo. Las Casas Consistoriales de Pedro de Artiaga”, Abrente, n. ${ }^{\circ}$ 26, 1994, pp. 159-174.

ABEL VILELA, A. DE: Urbanismo y arquitectura en Lugo. La Plaza Mayor. Sada, Ediciós do Castro, 1999.

ABEL VILELA, A. DE: “A etapa lucense de Lucas Antonio Ferro Caaveiro”, Lucensia, vol. 28, n. $^{\circ} 55,2017$, pp. $109-128$.

ÁLVAREZ CLAVIJO, M.T.: Logroño en el siglo XVI: arquitectura y urbanismo. Logroño, Gobierno de La Rioja, Ayuntamiento de Logroño, Instituto de Estudios Riojanos, 2003, vol. 2.

ARAMBURU EXPÓSITO, M.J.: Arte y piedad. El arte religioso en Bergara en la Edad Mo derna. Bergara, Ayuntamiento de Bergara, 2008, 2 t.

ARRAZOLA ECHEVERRÍA, M.A.: Renacimiento en Guipúzcoa. Arquitectura. San Sebastián, Diputación Foral de Guipúzcoa, 1988.

AYERZA ELIZARAIN, R.: Iglesias de madera en Gipuzkoa. Bilbao, Universidad del País Vasco, 2019.

BALLESTEROS IZQUIERDO, T.: Actividad artística en Vitoria durante el primer tercio del siglo XVII: Arquitectura. Vitoria-Gasteiz, Diputación Foral de Álava, 1990.

BARRIO LOZA, J.A., MOYA VALGAÑÓN, J.G.: "El modo vasco de producción arquitectónica en los Siglos XVI-XVIII”, Kobie, n. ${ }^{\circ}$ 10, 1980, pp. 283-369.

BARRIO LOZA, J.A., MOYA VALGAÑÓN, J.G.: "Los Canteros Vizcaínos (1500-1800): Diccionario Biográfico", Kobie, n. ${ }^{\circ} 11,1981$, pp. 173-282.

BARRIO LOZA, J.A. (Dir.): Bizkaia. Arqueología, urbanismo y arquitectura histórica. Bilbao, Universidad de Deusto-Deiker, Diputación Foral de Bizkaia, 1989-1991, 3 vols.

BEGOÑA, A. DE: Arquitectura doméstica en la Llanada de Álava. Siglos XVI, XVII y XVIII. Vitoria-Gasteiz, Diputación Foral de Álava, 1986.
CAGIGAS ABERASTURI, A.I.: Los maestros canteros de Trasmiera. Santander, Universidad de Cantabria, 2015. https://repositorio.unican.es/xmlui/handle/10902/8345 (Consultado el 01/06/2018).

CAL PARDO, E.: "Sacristía y Custodia de la Catedral Basílica de Mondoñedo", Estudio Mindonienses, n. ${ }^{\circ}$ 3, 1987, pp. 549-570.

CAL PARDO, E.: Catálogo de los documentos medievales, escritos en pergamino, del Archivo de la Catedral de Mondoñedo (871-1492). Lugo, Diputación Provincial de Lugo, 1990.

CAL PARDO, E.: Mondoñedo -Catedral, Ciudad, Obispado- en el siglo XVI. Catálogo de la documentación del Archivo Catedralicio. Santiago de Compostela, Xunta de Galicia, 1992.

CAL PARDO, E.: Episcopologio Mindoniense. Santiago de Compostela, CSIC-Xunta de Galicia, Instituto de Estudios Gallegos "Padre Sarmiento"; Mondoñedo-Ferrol, Estudios Mindonienses, 2003

CAL PARDO, E.: Tumbos de la Catedral de Mondoñedo. Tumbo Pechado. Transcripción integra de sus documentos. Tomos I y II. Lugo, Diputación Provincial de Lugo, 2006.

CALATAYUD FERNÁNDEZ, E.: Arquitectura religiosa en la Rioja Baja: Calahorra y su entorno (1500-1650). Madrid, Universidad Complutense de Madrid, 1987, 7 vols.

CALLES LOMBAO, M.G.: "La Torre de los Signos de la Santa Iglesia Catedral Basílica de Lugo (1575-1583), nuevos documentos localizados en los archivos lucenses", Abrente, n 49-50, 2017-2018, pp. 23-55

CARRERO SANTAMARÍA, E.: Las catedrales de Galicia durante la Edad Media. Claustros y entorno urbano. A Coruña, Fundación Pedro Barrié de la Maza, 2005

Casas consistoriales de Navarra. Pamplona, Gobierno de Navarra, 1998.

CASTRO SANTAMARÍA, A.: Juan de Álava. Arquitecto del Renacimiento. Salamanca, Caja Duero, 2002.

CENDOYA ECHANIZ, J.: Arquitectura conventual en Guipúzcoa (S. XVI-XVIII). Las franciscanas. San Sebastián, Editorial Franciscana Aránzazu, 1999. 
DÚO RÁMILA, D.: "Maestros canteros de Trasmiera en Galicia (siglo XVI)", Espacio, Tiempo y Forma. Serie VII, Historia del Arte, n. ${ }^{\circ}$ 24, 2011, pp. 81-100.

ECHEVERRÍA GOÑI, P.L., FERNÁNDEZ GRACIA, R.: "Arquitectura”, en FERNÁNDEZ GRACIA, R. (coord.): El arte del Renacimiento en Navarra. Pamplona, Gobierno de Navarra, 2005, pp. 75-184.

ECHEVERRÍA GOÑI, P.L., GONZÁLEZ DE ZÁRATE, J.M.: Vitoria renacentista. Vitoria-Gasteiz, Ayuntamiento de Vitoria-Gasteiz, 1985.

FERNÁNDEZ GASALLA, L., GOY DIZ, A.: "Las casas consistoriales de Santiago de Compostela en los siglos XVI y XVII”, Sémata, n. ${ }^{\circ} 15,2003$, pp. 545-586.

FERNÁNDEZ VILLALBA, J.I.: Mondoñedo, regreso al pasado. Recopilación de artículos publicados en diversos medios de comunicación por Don Eduardo Lence-Santar y Guitián. Mondoñedo, Museo Catedralicio y Diocesano de Mondoñedo, 1999-2000, 2 t.

FLÓREZ, H.: España Sagrada. Theatro Geographico Historico de la Iglesia de España. Origen, divisiones, y limites de todas sus Provincias. Antiguedad, Traslaciones, y estado antiguo $y$ presente de sus Sillas, con varias Disertaciones criticas. Tomo XVIII. De las Iglesias Britoniense, y Dumiense, incluidas en la actual de Mondoñedo. Madrid, Antonio Marín, 1764.

FORNELLS ANGELATS, M.: La Universidad de Oñati y el Renacimiento. Donostia-San Sebastián, Diputación Foral de Guipúzcoa, 1995.

GALLEGO DOMÍNGUEZ, O.: "Las casas consistoriales de la ciudad de Ourense", Boletín Auriense, n. ${ }^{\circ} 10,1980$, pp. 107-117.

GÓMEZ DARRIBA, J.: "El maestro trasmerano Pedro de Morlote y la nueva cabecera de la catedral de Mondoñedo", Quintana, n. ${ }^{\circ}$ 17, 2018, pp. 239-259.

GÓMEZ DARRIBA, J.: La ciudad de Mondoñedo en los siglos XVII y XVIII. Construcción y nueva imagen de un centro de poder episcopal. Santiago de Compostela, Universidade de Santiago de Compostela (Tesis Doctoral), 2020.

GÓMEZ DARRIBA, J.: “De piedra, arcos y agua. La construcción de puentes en el noreste de Galicia durante la Edad Moderna”, Santander. Estudios de Patrimonio, n. ${ }^{\circ}$ 3, 2020, pp. 233-276.
GONZÁLEZ DE ZÁRATE, J.M., RUIZ DE AEL, M.: Humanismo y arte en la Universidad de Oñate. Vitoria-Gasteiz, Instituto EPHIALTE, 1989.

GORDO PELÁEZ, L.J.: Equipamientos y edificios municipales en la Corona de Castilla en el siglo XVI. Madrid, Universidad Complutense de Madrid, 2010. http://eprints.ucm. es/10840/ (Consultado el 10/08/2020).

GOY DIZ, A.: "Los trasmeranos en Galicia: la familia de los Arce", en ARAMBURU-ZABALA HIGUERA, M.A. (Dir.): Juan de Herrera y su influencia. Actas del Simposio. Camargo, 14-17 julio 1992. Santander, Fundación Obra Pía Juan de Herrera, Universidad de Cantabria, 1993, pp. 147-163.

GOY DIZ, A.: "La difícil empresa de llevar el agua a la ciudad de Lugo: traídas, caños y fuentes”, en GOY DIZ, A., PATIÑO EIRÍN, C. (eds.): El tapiz humanista II. Actas del XI Curso de Primavera IV Centenario de la Segunda Parte del Quijote. Lugo 21-23 de abril de 2015. Santiago de Compostela, Universidade de Santiago de Compostela, 2017, pp. 121-158.

GOY DIZ, A.: "Fuentes y traídas, las arquitecturas del agua de la ciudad de Lugo: una propuesta de difusión patrimonial a partir de la recreación virtual", en PAYO HERNANZ R.J. et al. (eds.): Vestir la arquitectura. XXII Congreso Nacional de Historia del Arte. Burgos, Universidad de Burgos, 2019, vol. 2, pp. 1608-1614.

GOY DIZ, A.: "Proyecto para las Casas Consistoriales de Lugo (1570)", en IBÁÑEZ FERNÁNDEZ, J. (coord.): Trazas, muestras y modelos de tradición gótica en la Península Ibérica entre los siglos XIII y XVI. Madrid, Instituto Juan de Herrera, 2019, pp. 522-525.

LENCE-SANTAR Y GUITIÁN, E.: Mondoñedo: El Santuario de los Remedios. Mondoñedo, César G. Seco Romero, 1909.

LENCE-SANTAR Y GUITIÁN, E.: "La muralla de Mondoñedo", Boletín de la Comisión provincial de Monumentos Históricos y Artísticos de Lugo, t. 4, n. ${ }^{\circ} 33,1950$, pp. 23-30.

LÓPEZ ACUÑA, A.: "Las Casas Consistoriales lucenses", Boletín de la Comisión provincial de Monumentos Históricos y Artísticos de Lugo, t. 4, n. 33, 1950, pp. 56-62.

LÓPEZ DÍAZ, M.: "Poder e instituciones municipales: el concejo mindoniense en los siglos XVI y XVII”, Sémata, n. ${ }^{\circ} 15,2003$, pp. 415-444. 
MARTÍN MIGUEL, M.A.: Arte y Cultura en Vitoria durante el Siglo XVI. Vitoria-Gasteiz, Ayuntamiento de Vitoria-Gasteiz, 1998

MARTÍNEZ DE SALINAS OCIO, F.: Arquitectura y urbanismo de Laguardia (Álava). (De la Edad Media al primer tercio del siglo XIX). Vitoria-Gasteiz, Diputación Foral de Álava, 1991

MINTEGI LUENGO, N.: Las Casas consistoriales de las villas de Bizkaia. Bilbao, Ayuntamiento de Bilbao, 2009.

MORALES, A.J.: "El Ayuntamiento de Sevilla: maestros canteros, entalladores e imagineros", Laboratorio de Arte, n. ${ }^{\circ}$ 4, 1991, pp. 61-82.

MOYA VALGAÑÓN, J.G.: Arquitectura religiosa del siglo XVI en la Rioja Alta. Logroño, Instituto de Estudios Riojanos, 1980.

NOVO SÁNCHEZ, F.J.: "La traza de los antiguos retablos mayores clasicistas de dos iglesias parroquiales de Lalín: Santiago de Catasós y San Xoán de Vilanova”, Cuadernos de Estudios Gallegos, t. 50, fasc. 116, 2003, pp. 259-271.

NOVO SÁNCHEZ, F.J.: “Antigua casa consistorial (Mondoñedo)”, en SÁNCHEZ GARCÍA, J.A., VÁZQUEZ CASTRO, J., VIGO TRASANCOS, A. (eds.): Arquitecturas desvanecidas. Memoria gráfica del patrimonio desaparecido en Galicia. Madrid, Abada, 2019, pp. 327-345.

PEIRÓ GRANER, M.N.: "A poboación da cidade de Lugo no século XVI. Catro inventarios (1542, 1543, 1544 e 1587)”, Lucensia, n. ${ }^{\circ}$ 4, 1992, pp. 69-96.

PÉREZ COSTANTI, P.: Diccionario de artistas que florecieron en Galicia durante los siglos XVI y XVII. Santiago, Seminario C. Central, 1930.

PÉREZ RODRÍGUEZ, F.: "Noticias sobre tres arquitectos de la Ilustración gallega: Melchor de Prado y Mariño, Felipe Gianzo y Miguel Ángel de Uría”, Brigantium, n. ${ }^{\circ}$ 14, 2003, pp. 327-340.

POLO SÁNCHEZ, J.J.: "Aportaciones a la escultura renacentista en Cantabria: Simón de Bueras y Adrián de Bedoya”, Boletín del Seminario de Estudios de Arte y Arqueología, n. 52 , 1986, pp. 311-320.
REIGOSA MÉNDEZ, R.: "Las Casas de Consistorio de 1434 a 1587", Mondoñedo, n. ${ }^{\circ} 135$, 2018, pp. 8-9.

REIGOSA MÉNDEZ, R.: "La Muerte Negra en el Mondoñedo del s. XVI", Rudesindus, n. 12,2019 , pp. 225-252.

RÚA VELOSO, O.: Heráldica del Municipio de Mondoñedo. Lugo, Diputación Provincia de Lugo, 2005.

SAAVEDRA FERNÁNDEZ, P.: Economía, Política y Sociedad en Galicia: la provincia de Mondoñedo. Madrid, Xunta de Galicia, 1985.

SESMERO PÉREZ, F.: El arte del Renacimiento en Vizcaya. Bilbao, 1954.

SILVA POSADA, V. DE: "La Casa Consistorial de Mondoñedo", Galicia Diplomática, t. 5, n. ${ }^{\circ} 16-17,1893$, pp. 101-102.

SOBRADO CORREA, H.: La ciudad de Lugo en el Antiguo Régimen. Siglos XVI-XIX. Lugo, Diputación de Lugo, 2001.

TAÍN GUZMÁN, M.: As antigas Casas do Concello de Santiago de Compostela. A sede da praza de Cervantes (1689-1787). Santiago de Compostela, Concello de Santiago de Compostela, Universidade de Santiago de Compostela, 2003.

TARIFA CASTILLA, M.J.: La arquitectura religiosa del siglo XVI en la Merindad de Tudela. Pamplona, Gobierno de Navarra, 2005

URRESTI SANZ, V.: Arquitectura religiosa del Renacimiento en Álava (1530-1611). Vitoria-Gasteiz, Universidad del País Vasco, 2016.

https://addi.ehu.es/handle/10810/18582 (Consultado el 08/08/2020).

VÁZQUEZ SEIJAS, M.: Fortalezas de Lugo y su Provincia. (Notas arqueológicas, históricas y genealógicas). Lugo, La Voz de la Verdad, 1959, t. 2.

VIGO TRASANCOS, A. (Dir.): Planos y dibujos de arquitectura y urbanismo. Galicia en los Siglos XVI y XVII. Santiago de Compostela, Consello Galego de Colexios de Aparexadores e Arquitectos Técnicos, 2003. 
VILA JATO, M.D.: Lugo Barroco. Diputación Provincial de Lugo, Lugo, 1989.

VILA JATO, M.D.: “Canteros cántabros y vizcaínos en el primer Renacimiento gallego”, en Homenaje al Profesor Martín González. Valladolid, Universidad de Valladolid, 1995, pp. 275-277.

VILA JATO, M.D.: "La actividad artística en la provincia de Mondoñedo durante el Renacimiento", Estudios Mindonienses, n. ${ }^{\circ}$ 15, 1999, pp. 459-468. 